Metallurgical and Materials Transactions B, Vol. 34B, No. 5, Oct., 2003, pp. 685-705.

\title{
HEAT TRANSFER AND SOLIDIFICATION MODEL OF CONTINUOUS SLAB CASTING: CON1D
}

\author{
Ya Meng and Brian G. Thomas \\ University of Illinois at Urbana-Champaign, \\ Department of Mechanical and Industrial Engineering, \\ 1206 West Green Street, \\ Urbana, IL USA 61801
}

Ph: 217-333-6919; Fax: 217-244-6534; Email: bgthomas@uiuc.edu

\begin{abstract}
A simple, but comprehensive model of heat transfer and solidification of the continuous casting of steel slabs is described, including phenomena in the mold and spray regions. The model includes a 1-D transient finite-difference calculation of heat conduction within the solidifying steel shell coupled with 2-D steady-state heat conduction within the mold wall. The model features a detailed treatment of the interfacial gap between the shell and mold, including mass and momentum balances on the solid and liquid interfacial slag layers, and the effect of oscillation marks. The model predicts shell thickness, temperature distributions in the mold and shell, thickness of the re-solidified and liquid powder layers, heat flux profiles down the wide and narrow faces, mold water temperature rise, ideal taper of the mold walls, and other related phenomena. The important effect of non-uniform distribution of superheat is incorporated using the results from previous 3-D turbulent fluid flow calculations within the liquid pool. The FORTRAN program, CON1D, has a user-friendly interface and executes in less than a minute on a personal computer. Calibration of the model with several different experimental measurements on operating slab casters is presented along with several example applications. In particular, the model demonstrates that the increase in heat flux throughout the mold at higher casting speeds is caused by two combined effects: thinner interfacial gap near the top of the mold, and
\end{abstract}


thinner shell towards the bottom. This modeling tool can be applied to a wide range of practical problems in continuous casters.

\section{INTRODUCTION}

Heat transfer in the continuous slab casting mold is governed by many complex phenomena. Figure 1 shows a schematic of some of these. Liquid metal flows into the mold cavity through a submerged entry nozzle, and is directed by the angle and geometry of the nozzle ports ${ }^{[1]}$. The direction of the steel jet controls turbulent fluid flow in liquid cavity, which affects delivery of superheat to solid/liquid interface of the growing shell. The liquid steel solidifies against the four walls of the water-cooled copper mold, while it is continuously withdrawn downward at the casting speed.

Mold powder added to the free surface of the liquid steel melts and flows between the steel shell and the mold wall to act as a lubricant ${ }^{[2]}$, so long as it remains liquid. The resolidified mold powder, or "slag", adjacent to the mold wall cools and greatly increases in viscosity, thus acting like a solid. It is thicker near and just above the meniscus, where it is called the "slag rim". The slag cools rapidly against the mold wall forming a thin solid glassy layer, which can devitrify to form a crystalline layer if its residence time in the mold is very long ${ }^{[3]}$. This relatively solid slag layer often remains stuck to the mold wall, although it is sometimes dragged intermittently downward at an average speed less than the casting speed ${ }^{[4]}$. Depending on its cooling rate, this slag layer may have a structure that is glassy, crystalline or a combination of both ${ }^{[5]}$. So long as the steel shell remains above its crystallization temperature, a liquid slag layer will move downward, causing slag to be consumed at a rate balanced by the replenishment of bags of solid powder to the top surface. Still more slag is captured by the oscillation marks and other imperfections of the shell surface and carried downward at the casting speed. 
These layers of mold slag comprise a large resistance to heat removal, although they provide uniformity relative to the alternative of an intermittent vapor gap found with oil casting of billets. Heat conduction across the slag depends on the thickness and conductivity of its layers, which in turn depends on their velocity profile, crystallization temperature ${ }^{[6]}$, viscosity, and state (glassy, crystalline or liquid). The latter can be determined by the Time-Temperature-Transformation (TTT) diagram measured for the slag, knowing the local cooling rate ${ }^{[7-9]}$. Slag conductivity depends mainly on the crystallinity of the slag layer and on the internal evolution of its dissolved gas to form bubbles.

Shrinkage of the steel shell away from the mold walls may generate contact resistances or air gaps, which act as a further resistance to heat flow, especially after the slag is completely solid and unable to flow into the gaps. The surface roughness depends on the tendency of the steel shell to "ripple" during solidification at the meniscus to form an uneven surface with deep oscillation marks. This depends on the oscillation practice, the slag rim shape and properties, and the strength of the steel grade relative to ferrostatic pressure, mold taper, and mold distortion. These interfacial resistances predominantly control the rate of heat flow in the process.

Finally, the flow of cooling water through vertical slots in the copper mold withdraws the heat and controls the temperature of the copper mold walls. If the "cold face" of the mold walls becomes too hot, boiling may occur, which causes variability in heat extraction and accompanying defects. Impurities in the water sometimes form scale deposits on the mold cold face, which can significantly increase mold temperature, especially near the meniscus where the mold is already hot. After exiting the mold, the steel shell moves between successive sets of alternating support rolls and spray nozzles in the spray zones. The accompanying heat extraction causes surface temperature variations while the shell continues to solidify. 
It is clear that many diverse phenomena simultaneously control the complex sequence of events which govern heat transfer in the continuous casting process. The present work was undertaken to develop a fast, simple, and flexible model to investigate these heat transfer phenomena. In particular, the model features a detailed treatment of the interfacial gap in the mold, which is the most important thermal resistance. The model includes heat, mass, momentum and force balances on the slag layers in the interfacial gap.

This model is part of a larger comprehensive system of models of fluid flow, heat transfer, and mechanical behavior, which is being developed and applied to study the formation of defects in the continuous casting process. These other models are used to incorporate the effects of mold distortion $^{[10]}$, the influence of fluid flow in the liquid pool on solidification of the shell ${ }^{[11]}$, and coupled thermal stress analysis of the shell to find the reduction of heat transfer across the interface due to air gap formation ${ }^{[12]}$.

This paper first describes the formulation of this model, which has been implemented into a user-friendly FORTRAN program, CON1D, on personal computers and UNIX workstations. Then, validation of the model with analytical solutions and calibration with example plant measurements are presented. Finally the effect of casting speed on mold heat transfer is investigated as one example of the many applications of this useful modeling tool.

\section{PREVIOUS WORK}

Many mathematical models have been developed of the continuous casting process, which are partly summarized in previous literature reviews ${ }^{[13-15]}$. Many continuous casting models are very sophisticated (even requiring supercomputers to run) so are infeasible for use in an operating environment. The earliest solidification models used 1-D finite difference methods to calculate the temperature field and growth profile of the continuous cast steel shell[16,17]. Many industrial models followed ${ }^{[18,19]}$. These models first found application in the successful prediction 
of metallurgical length, which is also easily done by solving the following simple empirical relationship for distance, $z$, with the shell thickness, $S$, set to half the section thickness.

$$
S=K \sqrt{z / V_{c}}
$$

where $K$ is found from evaluation of breakout shells and computations. Such models found further application in trouble shooting the location down the caster of hot tear cracks initiating near the solidification front ${ }^{[20]}$, and in the optimization of cooling practice below the mold to avoid subsurface longitudinal cracks due to surface reheating ${ }^{[21]}$.

Since then, many advanced models have been developed to simulate further phenomena such as thermal stress and crack related defects ${ }^{[12,22,23]}$ or turbulent fluid flow ${ }^{[24-28]}$ coupled together with solidification. For example, a 2-D transient stepwise coupled elasto-viscoplastic finiteelement model tracks the behavior of a transverse slice through a continuously cast rectangular strand as it moves down through the mold at casting speed ${ }^{[12]}$. This model is suited for simulating longitudinal phenomena such as taper design ${ }^{[29]}$, longitudinal cracks $^{[30]}$ and surface depressions ${ }^{[31]}$. Other casters have been modeled using 3-D coupled fluid flow - solidification models ${ }^{[27]}$ based on control-volume or finite difference approaches at the expense of greater computation time and memory.

To study temperature distribution and/or distortion of the mold, 3-D finite-element thermalstress models have been applied ${ }^{[10,32]}$. These models have been crucial in determining the axial heat flux profile based on measured temperatures in the mold walls ${ }^{[20,32,33]}$. This procedure is sometimes automated with inverse heat conduction models ${ }^{[20]}$.

One of the greatest resistances to heat transfer from the liquid steel to the mold cooling water is the interface between the mold and shell. Heat transfer across this interface is controlled by the thickness and thermal properties of the materials that fill the gap. Despite its known importance, most previous mathematical models characterize the interface as a boundary condition for a 
model of either the shell or the mold alone. Even models of both usually use a simplified treatment of the gap ${ }^{[34-36]}$.

A few models have considered more detailed treatment of the resolidified powder layers in the gap, and calculate slag layer thicknesses ${ }^{[37,38]}$, slag velocity profile along the film thickness ${ }^{[38,}$ 39] and interface friction ${ }^{[37-39]}$. Common oversimplifications include neglecting the solid slag layer ${ }^{[40]}$, assuming constant slag layer thickness ${ }^{[39]}$, or assuming constant slag viscosity ${ }^{[41,42]}$. The highly temperature-dependent slag viscosity has been modeled with a simple inverse function of temperature $^{[38]}$ or with an Arrhenius equation ${ }^{[37,39,43]}$, by fitting the low viscosities (usually less than $10 \mathrm{~Pa} \cdot \mathrm{s}$ ) measured at high temperature and then extrapolating to lower temperatures. Even the best interface models generally oversimplify the shell and/or the mold. Thus, there is a need for a comprehensive model of the shell, mold, and gap, which is fast and easy to run, for use in both research and steel plant environments.

\section{MODEL FORMULATION}

The model in this work computes 1-D transient heat flow through the solidifying steel shell, coupled with 2-D steady-state heat conduction within the mold wall. Superheat from the liquid steel was incorporated as a heat source at the steel solid/liquid interface. The model features a detailed treatment of the interfacial gap, including mass and momentum balances on the liquid and solid slag layers, friction between the slag and mold, and slag layer fracture. The model simulates axial (z) behavior down a chosen position on the mold perimeter. Wide-face, narrowface and even corner simulations can thus be conducted separately.

\section{A Superheat Delivery}

Before it can solidify, the steel must first cool from its initial pour temperature to the liquidus temperature. Due to turbulent convection in the liquid pool, this "superheat" contained in the 
liquid is not distributed uniformly. A small database of results from a 3-D fluid flow model ${ }^{[11]}$ is used to determine the heat flux, $q_{s h}$, delivered to the solid/liquid interface due to the superheat dissipation, as a function of distance below the meniscus. The initial condition of the liquid steel at the meniscus is then simply the liquidus temperature.

Previous work ${ }^{[11]}$ found that this "superheat flux" varies linearly with superheat temperature difference and also is almost directly proportional to casting speed. The superheat flux function in the closest database case is adjusted to correspond with the current superheat temperature difference, $\Delta T_{\text {sup }}$, and casting speed, $V_{c}$, as follows:

$$
q_{s h}=q_{s h}^{o} \frac{\Delta T_{\text {sup }}}{\Delta T_{\text {sup }}^{o}} \frac{V_{c}}{V_{c}^{o}}
$$

where $q_{s h}^{o}$ is the superheat flux profile from the database case with conditions of superheat temperature difference $\Delta T_{\text {sup }}^{o}$ and casting speed $V_{c}^{o}$. Further adjustments are made to translate the heat flux peak to account for differences in nozzle configuration between the current conditions and the database. Examples of the superheat flux function are included in Fig.2, which represents results for a typical bifurcated, downward-directed nozzle. The influence of this function is insignificant to shell growth over most of the wide face, where the superheat flux is small and contact with the mold is good.

\section{B Heat Conduction in the Solidifying Steel Shell}

Temperature in the thin solidifying steel shell is governed by the 1-D transient heat conduction equation, which becomes the following on applying the chain rule to the temperature-dependent conductivity:

$$
\rho_{\text {steel }} C p_{\text {steel }}^{*} \frac{\partial T}{\partial t}=k_{\text {steel }} \frac{\partial^{2} T}{\partial x^{2}}+\frac{\partial k_{\text {steel }}}{\partial T}\left(\frac{\partial T}{\partial x}\right)^{2}
$$


Temperature dependent properties are given in Appendix $\mathrm{D}^{[44,45]}$. Both sensible and latent heat of steel are included in the effective specific heat, $C p_{\text {steel }}^{*}$, explained in Section IV-C.

This equation assumes that axial $(\mathrm{z})$ heat conduction is negligible in the steel, which is reasonable past the top $10 \mathrm{~mm}$, due to the large advection component as indicated by the large Péclet number: $P e=\frac{V_{c} Z_{\text {mold }} \rho_{\text {steel }} C p_{\text {steel }}}{k_{\text {steel }}}=\frac{0.0167 \times 0.81 \times 7400 \times 670}{30}=2236 . \quad$ The simulation domain for this portion of the model is a slice through the liquid steel and solid shell, which moves downward at the casting speed, as pictured in Figs. 2 and A-1 together with typical interface conditions. At the internal solid/liquid steel interface, the "superheat flux", $q_{s h}$, delivered from the turbulent liquid pool, (Section III A), is imposed as a source term. From the external surface of the shell, interfacial heat flux, $q_{\text {int }}$, is lost to the gap, which depends on the mold and slag layer computations, described in the following two sections. Appendix A provides the explicit finite-difference solution of Eq.3, including both of these boundary conditions.

\section{Heat transfer Across the Interfacial Gap}

Heat transfer across the interfacial gap governs the heat flux leaving the steel, $q_{\text {int }}$, to enter the mold. To calculate this at every position down the mold, the model evaluates an effective heat transfer coefficient, $h_{\text {gap }}$, between the surface temperature of the steel shell, $T_{s}$, and the hot face of the mold wall, $T_{\text {mold: }}$ :

$$
\begin{aligned}
& q_{\text {int }}=h_{\text {gap }}\left(T_{s}-T_{\text {mold }}\right) \\
& h_{\text {gap }}=1 /\left(\left(r_{\text {contact }}+\frac{d_{\text {air }}}{k_{\text {air }}}+\frac{d_{\text {solid }}}{k_{\text {solid }}}\right)+1 /\left(1 /\left(\frac{d_{\text {liquid }}}{k_{\text {liquid }}}+\frac{d_{\text {eff }}}{k_{\text {eff }}}\right)+h_{\text {rad }}\right)\right)
\end{aligned}
$$

Heat conduction depends on the thermal resistances of four different layers of materials contained in the gap: oscillation marks, liquid slag, solid slag and a possible air gap. These 
depend on the time-averaged thickness profiles down the mold of the different layers and their corresponding thermal conductivities. The model for gap heat conduction is illustrated in Figs.3 and 6. The most important resistances are usually the slag layers, whose thicknesses are calculated as described in the next section. The latent heat evolved by liquid slag solidification is less than $3 \%$ of the heat transferred across the gap, so it is neglected in this model.

The equivalent air gap, $d_{\text {air }}$, is specified as input data and includes contact resistances ${ }^{[46]}$ at the slag/shell and slag/mold interfaces. It may also include a gap due to shrinkage of the steel shell, which can be calculated using a separate thermal-stress model ${ }^{[12]}$. The shrinkage gap is affected by the mold taper and also by mold distortion, which can be calculated by another model ${ }^{[10]}$. This gap is important when simulating down positions near the corner.

All non-uniformities in the flatness of the shell surface are incorporated into the model through the prescribed oscillation mark depth, $d_{\text {mark }}$, and width, $L_{\text {mark, }}$, as pictured in Fig.4. Assuming shallow triangle-shaped marks or depressions, $d_{o s c}$ is the volume-averaged oscillation mark depth:

$$
d_{\text {osc }}=\frac{0.5 L_{\text {mark }} d_{\text {mark }}}{L_{\text {pitch }}}
$$

where $L_{\text {pitch }}$ is the ratio of the casting speed $V_{c}$ to the oscillation frequency, freq.

The oscillation marks affect heat transfer in two different ways. Firstly, the oscillation marks consume mold slag, so affect the slag layer thicknesses, as described in section F. Secondly, they reduce heat conduction by effectively providing an extra gap. This extra gap is represented by $d_{\text {eff, }}$ calculated based on a heat balance ${ }^{[47]}$ which produces the same total heat flux as found by combining the heat fluxes across the two parallel conduction paths (at or adjacent to the oscillation mark), averaged spatially (z-direction) using an appropriate weighted average. 


$$
\begin{aligned}
& d_{\text {eff }}=\frac{0.5 L_{\text {mark }} d_{\text {mark }}}{\left(L_{\text {pitch }}-L_{\text {mark }}\right)\left(1+0.5 \frac{d_{\text {mark }}}{d_{\text {liquid }}+d_{\text {solid }}} \frac{k_{\text {gap }}}{k_{\text {mark }}}\right)+L_{\text {mark }}} \\
& k_{\text {gap }}=\left(d_{\text {liquid }}+d_{\text {solid }}\right) /\left(\frac{d_{\text {solid }}}{k_{\text {solid }}}+1 /\left(\frac{k_{\text {liquid }}}{d_{\text {liquid }}}+h_{\text {rad_liquid }}\right)\right)
\end{aligned}
$$

The oscillation marks are assumed to be filled with either slag, air, or a mixture, depending on the local shell surface temperature. This governs the value of $k_{\text {mark }}$.

Except for perhaps a microscopically thin glassy surface layer, experience has shown that the cold slag layer adjacent to the mold wall is usually crystalline ${ }^{[48,49]}$, and thus opaque. Thus, radiation occurs only across the semi-transparent hot glassy or liquid layer above $T_{f s o l}^{[50,51]}$, according to Eq.9, as shown in Fig.3:

$$
h_{\text {rad }}=\frac{m^{2} \sigma\left(T_{s K}^{2}+T_{\text {fsol } K}^{2}\right)\left(T_{s K}+T_{\text {fsol } K}\right)}{0.75 a\left(d_{\text {liquid }}+d_{\text {eff }}\right)+\frac{1}{\varepsilon_{\text {slag }}}+\frac{1}{\varepsilon_{\text {steel }}}-1} \quad\left(T_{\text {mold }}<T_{\text {fsol }}\right)
$$

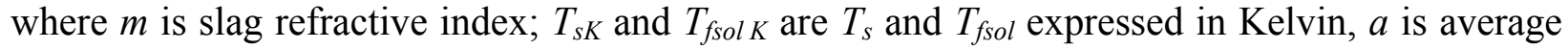
absorption coefficient of the slag, assuming graybody radiation $\left(\varepsilon_{\text {slag }}=0.9\right)$. If the liquid slag runs out, so that $T_{s}<T_{\text {fsol }}$, then $h_{\text {rad }}=0$. In the unlikely event that $T_{\text {mold }} \geq T_{\text {fsol }}, \varepsilon_{\text {slag }}$ would be replaced by $\varepsilon_{m o l d}$, and $T_{f s o l}$ by $T_{\text {mold }}$ in Eq.9. Jenkins showed that this simple equation to characterize radiation with absorption across a gap, Eq.9, is accurate to within $10 \%$ relative to a full multiview factor analysis including radiation-conduction ${ }^{[52]}$. This is sufficiently accurate because the radiation component itself usually contributes only on the order of $10 \%$ of the gap heat transfer. 


\section{Mass and Momentum Balance on Powder Slag Layers}

Slag is assumed to flow down the gap as two distinct layers: solid and liquid. The solid layer is assumed to move at a time-average velocity, $V_{\text {solid, }}$, which is always between zero and the casting speed, $V_{c}$, according to the input solid slag speed ratio, $f_{v}$.

$$
V_{\text {solid }}=f_{v} \cdot V_{c}
$$

The downward velocity profile across the liquid slag layer is governed by the simplified Navier-Stokes equation, assuming laminar Couette flow:

$$
\frac{\partial}{\partial \mathrm{x}}\left(\mu \frac{\partial V_{z}}{\partial \mathrm{x}}\right)=\left(\rho_{\text {steel }}-\rho_{\text {slag }}\right) g
$$

A small body force opposing flow down the wide face gap is created by the difference between the ferrostatic pressure from the liquid steel, $\rho_{\text {steel }} g$, transmitted through the solid steel

shell, and the average weight of the slag, $\rho_{\text {slag }} g$. The time-average velocity of the liquid slag described by Eq.11, $V_{z}$, is subjected to boundary conditions constraining it to the casting speed, $V_{c}$ on its hot side and to the solid slag velocity, $V_{\text {solid }}$ on its cold side.

The viscosity of the molten slag, $\mu(T)$, is assumed to vary exponentially with temperature:

$$
\mu=\mu_{o}\left(\frac{T_{o}-T_{f s o l}}{T-T_{f s o l}}\right)^{n}
$$

where the parameters $T_{f s o l}$ and $n$ are chosen empirically to fit measured data and $\mu_{o}$ is the viscosity measured at the reference temperature, $T_{o}$, usually chosen to be $1300^{\circ} \mathrm{C}$. A typical curve obtained with this function is shown in Fig.5 together with the measured viscosities by Lanyi that it was fit to match ${ }^{[53]}$. Mold slag in service absorb some $\mathrm{Al}_{2} \mathrm{O}_{3}$ from the steel, which changes their properties, including decreasing the solidification temperature ${ }^{[33,54]}$. The second curve in Fig.5 was constructed for a reported solidification temperature $T_{f s o l}$ of $1045^{\circ} \mathrm{C}$ and viscosity at $1300^{\circ} \mathrm{C}$ of 1.1 Poise, and was used later in model calibration. 
By approximating temperature across the gap to vary linearly, Eqs.10-12 can be solved for the time-averaged velocity distribution across the slag layers, which is illustrated in Fig.6. Integrating across the liquid region yields an average velocity for the liquid layer, $\bar{V}_{\text {liquid }}$ :

$$
\bar{V}_{\text {liquid }}=\frac{\left(\rho_{\text {slag }}-\rho_{\text {steel }}\right) g d_{\text {liquid }}^{2}}{\mu_{s}(n+2)^{2}(n+3)}+\frac{V_{c}+V_{\text {solid }}(n+1)}{(n+2)}
$$

where $\mu_{s}$ is the slag viscosity at liquid layer/steel shell interface. A mass balance was imposed to match the measured (known) powder consumption, $Q_{\text {slag }}\left(\mathrm{kg} / \mathrm{m}^{2}\right)$, with the total molten slag flow rate past every location down the interfacial gap, neglecting the carbon content component, which burns off. This consumption rate is expressed as mass of slag per unit area of the strand surface, which can be found from the consumption per mass of product, $M_{\text {slag }}(\mathrm{kg} / \mathrm{ton})$ :

$$
Q_{\text {slag }}\left(\mathrm{kg} / \mathrm{m}^{2}\right)=M_{\text {slag }}(\mathrm{kg} / \text { ton }) \times \rho_{\text {steel }} \times \frac{W \times N}{2(W+N)}
$$

where $W$ is slab width and $N$ is slab thickness. Slag can be carried downward by the solid layer, the liquid layer, and in the oscillations marks:

$$
\frac{Q_{\text {slag }} \times V_{c}}{\rho_{\text {slag }}}=V_{\text {solid }} d_{\text {solid }}+\bar{V}_{\text {liquid }} d_{\text {liquid }}+V_{c} d_{\text {osc }}
$$

The liquid and solid layer thicknesses are obtained by solving a fourth order polynomial equation found by combining Eqs.5 and 15. The transport of slag by the oscillation marks depends on the lubrication state, discussed next.

Three different regions are distinguished down the mold, according to the lubrication condition. Close to the meniscus, a solid slag rim exists against the mold wall. Its thickness profile must be specified, as it depends on transient phenomena not yet in the model.

The second region, shown in Fig.6, allows the solid slag layer to move at the slow time averaged velocity $V_{\text {solid. }}$ It always also includes oscillation marks filled with molten slag and a 
continuous liquid slag layer, which remains present so long as the outer surface temperature of the steel $T_{s}$ ' exceeds the slag solidification temperature, $T_{f s o l}$ :

$$
T_{s}^{\prime}=T_{s}-q_{\text {int }} \cdot \frac{d_{e f f}}{k_{\text {mark }}}
$$

Slag in the oscillation marks remains liquid longer, due to the higher local shell temperature at their roots, $T_{s}$. Once the oscillation mark roots cool below the slag solidification temperature, however, the slag entrapped in them solidifies. This defines the third region, which consists of totally solid slag, moving downward at the uniform speed, $V_{\text {solid }}$. The oscillation marks no longer transport slag, so become filled with air. The transition between the second and third regions is gradual.

It is important to emphasize that this model represents steady, time-averaged behavior only. To investigate transient phenomena, a transient version of this model is being developed to calculate stress inside the slag layer based on force balance with friction, which is described elsewhere ${ }^{[55]}$.

\section{E Heat Conduction in the Mold}

Two dimensional, steady state temperature within a rectangular vertical section through the upper portion of the mold is calculated assuming constant conductivity:

$$
\frac{\partial^{2} T}{\partial x^{2}}+\frac{\partial^{2} T}{\partial z^{2}}=0
$$

This equation is solved using a standard Fourier series product solution ${ }^{[56]}$ applying fixed heat

flux, $q_{\text {int }}=-k_{\text {mold }} \partial T / \partial x$, and convection, $h_{\text {water }}$ and $T_{\text {water }}$ as boundary conditions, as shown in Fig.7a. This copper domain is generally chosen to extend from the top of the mold to $100 \mathrm{~mm}$ below the meniscus. Below this meniscus region, heat flow is one-dimensional through the thickness. Temperature at the copper hot face, $T_{\text {hotc }}$, is then: 


$$
T_{\text {hotc }}=T_{\text {water }}+q_{\text {int }}\left(\frac{1}{h_{\text {water }}}+\frac{d_{\text {mold }}}{k_{\text {mold }}}\right)
$$

where $d_{\text {mold }}$ is the copper mold thickness calculated in Appendix B. Coating layers are incorporated as needed to find the mold hot face temperature, $T_{\text {mold }}$, by adding extra $d_{\text {coat }} / k_{\text {coat }}$ resistances to Eq.18 as needed. In addition to the heat flux across the interface, $q_{\text {int }}$, this calculation requires the initial cooling water temperature, $T_{\text {water }}$, input as a boundary condition, and the effective water heat transfer coefficient, $h_{\text {water }}$, discussed next.

\section{F Convection to the Cooling Water}

The effective heat transfer coefficient between the cooling water and the cold face ("waterside") of the mold, $h_{\text {water }}$, is calculated including a possible resistance due to scale deposits on the surface of the cooling water channels:

$$
h_{\text {water }}=1 /\left(\frac{d_{\text {scale }}}{k_{\text {scale }}}+\frac{1}{h_{\text {fin }}}\right)
$$

To account for the complex nature of heat flow in the undiscretized width direction of the mold, the heat transfer coefficient between the mold cold face and the cooling water, $h_{f i n}$, incorporates heat flow to both the root and sides of the water channels, the latter treated as heattransfer fins.

$$
h_{\text {fin }}=\frac{h_{w} w_{c h}}{L_{c h}}+\frac{\sqrt{2 h_{w} k_{\text {mold }}\left(L_{c h}-w_{c h}\right)}}{L_{c h}} \tanh \sqrt{\frac{2 h_{w} d_{c h}^{2}}{k_{\text {mold }}\left(L_{c h}-w_{c h}\right)}}
$$

where the mold geometry parameters, $L_{c h}, w_{c h}$, and $d_{c h}$ are shown in Fig.7b. The heat transfer coefficient between the water and the sides of the water channel, $h_{w}$, is calculated assuming turbulent flow through an equivalent-diameter pipe using the empirical correlation of Sleicher and Reusse ${ }^{[57]}$, which is reported ${ }^{[58]}$ to be more accurate than other relations such as Dittus and Boelter ${ }^{[59]}$ : 


$$
h_{w}=\frac{k_{\text {water }}}{D}\left(5+0.015 \operatorname{Re}_{\text {waterf }}^{c_{1}} \operatorname{Pr}_{\text {waterw }}^{c_{2}}\right)
$$

where $D=\frac{2 w_{c h} d_{c h}}{w_{c h}+d_{c h}} \quad$ is the equivalent diameter of the water channel, $c_{1}=0.88-0.24 /\left(4+\operatorname{Pr}_{\text {waterw }}\right), \quad c_{2}=0.333+0.5 e^{-0.6 \mathrm{P}_{\text {ruaterw }}}$ are empirical constants.

The presence of the water slots can either enhance or diminish the heat transfer, relative to a tube mold with uniform thickness, $d_{\text {mold }}$ such as used in billet casting. Deep, closely spaced slots augment the heat transfer coefficient, $\left(h_{f i n}\right.$ larger than $\left.h_{w}\right)$ while shallow, widely spaced slots inhibit heat transfer. In most molds, $h_{f i n}$ and $h_{w}$ are very close.

Although it slightly underpredicts mold temperature, Eq.20 was shown, through comparison with many 3-D computations for a variety of typical slab casting mold geometries and conditions, to match the temperature within $1 \%$ at the water slot root and from $0.1 \%$ to $6 \%$ at the hot face ${ }^{[47,60]}$. For a typical hot face temperature of $190^{\circ} \mathrm{C}$ and water temperature of $30^{\circ} \mathrm{C}$, it gives maximum errors of $2^{\circ} \mathrm{C}$ and $10^{\circ} \mathrm{C}$. It is most accurate for molds with either deep, closely-spaced slots $^{[47]}$ or very wide slots ${ }^{[60]}$, where cold face temperature is most nearly constant as assumed in Eq.20.

\section{G Spray zones below the mold}

Below the mold, heat flux from the strand surface varies greatly between each pair of support rolls according to spray nozzle cooling (based on water flux), $h_{\text {spray }}$; radiation, $h_{\text {rad_spray }}$; natural convection, $h_{\text {conv }}$; and heat conduction to the rolls, $h_{\text {roll }}$, as shown in Fig.8. Incorporating these phenomena enables the model to simulate heat transfer during the entire continuous casting process. The heat extraction due to water sprays is a function of water flow ${ }^{[61]}$, of the following form:

$$
h_{\text {spray }}=A \cdot Q_{\text {water }}^{c} \cdot\left(1-b \cdot T_{\text {spray }}\right)
$$


where $Q_{\text {water }}\left(1 / \mathrm{m}^{2} \mathrm{~s}\right)$ is water flux in spray zones, $T_{\text {spray }}$ is the temperature of the spray cooling water. In Nozaki's empirical correlation ${ }^{[62]}, \mathrm{A}=0.3925, \mathrm{c}=0.55, \mathrm{~b}=0.0075$, which has been used successfully by other modelers ${ }^{[61,63]}$.

Radiation is calculated by:

$$
h_{\text {rad_spray }}=\sigma \cdot \varepsilon_{\text {steel }}\left(T_{s K}+T_{\text {ambK }}\right)\left(T_{s K}^{2}+T_{\text {spray }}^{2}{ }^{2}\right)
$$

where $T_{s K}$ and $T_{\text {sprayK }}$ are $T_{s}$ and $T_{\text {spray }}$ expressed in Kelvin. Natural convection is treated as a constant input for every spray zone. For water-cooling only, it is not very important, so was simplified to $8.7 \mathrm{~W} / \mathrm{m}^{2} \mathrm{~K}$ everywhere. Larger values can be input for $h_{\text {conv }}$ to reflect the stronger convection when there is air mist in the cooling zone. Heat extraction into the rolls is calculated based on the fraction of heat extraction to the rolls, $f_{\text {roll }}$, which is calibrated for each spray zone:

$$
h_{\text {roll }}=\frac{\left(h_{\text {rad_spray }}+h_{\text {conv }}+h_{\text {spray }}\right) \cdot L_{\text {spray }}+\left(h_{\text {rad_spray }}+h_{\text {conv }}\right) \cdot\left(L_{\text {spray pitch }}-L_{\text {spray }}-L_{\text {roll contact }}\right)}{L_{\text {roll contact }} \cdot\left(1-f_{\text {roll }}\right)} \cdot f_{\text {roll }}
$$

A typical $f_{\text {roll }}$ value of 0.05 produces local temperature drops beneath the rolls of about $100^{\circ} C$. Beyond the spray zones, heat transfer simplifies to radiation and natural convection.

\section{H Solution Methodology}

The model requires simultaneous solution of three different systems of equations: 1-D transient heat conduction and solidification of the steel shell, 2-D steady state heat conduction in the mold, and the equations balancing heat, mass and momentum in the gap. The simulation starts by setting the initial steel and mold temperatures to the pouring temperature and inlet cooling water temperature respectively. Phase transformation temperatures and phase fraction temperature curves are then calculated, using one of the methods described in the next section. Then, each time step begins by rearranging and solving Eqs.5 and 15 simultaneously for $d_{\text {liquid }}$ and $d_{\text {solid }}$, based on heat and mass balance at the previous time step. The heat flux $q_{\text {int }}$ is then 
calculated according to Eqs.4 and 5, which is the boundary condition for both steel and mold domains. The heat transfer coefficient, $h_{\text {water }}$ is calculated according to cooling channel conditions with Eqs.19 to 21, and used to obtain mold temperatures. Applying the superheat flux boundary condition, Eq.2, as an internal heat source at the steel solid/liquid interface, the model uses an explicit, central-finite difference algorithm originally developed by Pehlke ${ }^{[64]}$ to solve Eq.3 for the shell temperature at each time step (Appendix A). This limits the maximum time step size, $\Delta t$. When a node temperature drops below the liquidus temperature, its solid fraction is calculated from the latent heat evolved, and then the node temperature is adjusted ${ }^{[65]}$ (Eq.A6) according to the phase fraction-temperature curves, described in section IV-A. The results are used as initial conditions for the 2-D mold calculation, which solves Eq.17 analytically, relating distance down the mold, $\mathrm{z}$, to time in the shell through the casting speed. Subsequently, the entire 1-D shell solidification model in the 2-D mold region is recomputed using the new 2-D mold temperatures as its boundary condition. This stepwise coupling procedure alternates between models until the 1-D mold temperatures converge to match the 2-D results within $3^{\circ} \mathrm{C}$. This produces a self-consistent prediction, which is stable for all coupled simulations investigated and usually converges in 3-4 iterations. Figure 9 gives a flow chart of the whole procedure.

The model has been incorporated into a user-friendly FORTRAN program, CON1D ${ }^{[66]}$. A 100-second long simulation with 0.004 sec time step and 100-node mesh runs on a Pentium III personal computer (using 3.1Mbytes of memory) in about 30 seconds.

\section{STEEL PROPERTIES}

The program includes several different choices for steel properties, including simple constants input by the user. By default, the liquidus temperature, solidus temperature, phase fraction curve, thermal conductivity, specific heat and thermal linear expansion are all calculated 
as functions of composition and temperature. Steel density, $\rho_{\text {steel }}$, latent heat, $L_{f}$, and steel surface emissivity, $\varepsilon_{\text {steel }}$, are constants. For carbon steel: $\rho_{\text {steel }}=7400 \mathrm{~kg} / \mathrm{m}^{3}, L_{f}=271 \mathrm{~kJ} / \mathrm{kg}, \varepsilon_{\text {steel }}=0.8$

\section{A Phase Fraction}

By default, equilibrium lever-rule calculations are performed on an Fe-C phase diagram, whose phase field lines are specified as simple linear functions of alloy content (including the influences of $\mathrm{Si}, \mathrm{Cr}, \mathrm{Mn}, \mathrm{Ni}, \mathrm{Mo}, \mathrm{Cu}, \mathrm{Ti}, \mathrm{P}, \mathrm{S}, \mathrm{Al}, \mathrm{V}, \mathrm{N}, \mathrm{Nb}$ and $\mathrm{W}$ ) reported by Kagawa and Okamoto $^{[67]}$ in order to calculate steel liquidus, solidus, peritectic temperature and phase fractions. Alternatively, the user can choose a non-equilibrium micro-segregation model to find these values, based on an analytical Clyne-Kurz style equation developed by Won and Thomas ${ }^{[68]}$, which was extended in this work to include the effects of 14 elements, given in Appendix C. For a $0.044 \% \mathrm{C}, 0.022 \% \mathrm{Mn}, 0.006 \% \mathrm{~S}, 0.01 \% \mathrm{P}, 0.009 \% \mathrm{Si} 0.049 \% \mathrm{Al}$ plain carbon steel, the equilibrium phase diagram model calculates $T_{l i q}=1528^{\circ} \mathrm{C}, T_{s o l}=1509^{\circ} \mathrm{C}$, while with $10^{\circ} \mathrm{C} /$ second cooling rate, the segregation model gives $T_{\text {liq }}=1532^{\circ} \mathrm{C}, T_{\text {sol }}=1510^{\circ} \mathrm{C}$. Figure 10 shows the solid fraction temperature curve in the mushy zone obtained from both models. Both models produce similar results. The surprising finding that the equilibrium model produces slightly lower transformation temperatures shows that differences in the coefficients which define the alloy-dependent equilibrium lines are more important than the non-equilibrium effects due to segregation at the typical cooling rates, dendrite arm spacing, and compositions considered.

\section{B Thermal Conductivity of Steel}

The thermal conductivity of carbon steel is calculated as a function of temperature, carbon content and phase fraction, which was fitted from measured data compiled by K. Harste ${ }^{[44]}$. The specific functions are listed in Appendix D. Stainless steel thermal conductivity is calculated 
according to fitted equation based on measured data compiled by Pehlke ${ }^{[45]}$. Figure 11 compares some typical plain-carbon steel, austenitic-stainless steel and ferritic stainless steel conductivities. Thermal conductivity of the liquid is not artificially increased, as common in other models, because the effect of liquid convection is accounted for in the superheat flux function, which is calculated by models which fully incorporate the effects of turbulent flow.

\section{Effective Specific Heat of Steel}

Specific heat is calculated as a function of temperature, carbon content, phase fraction and steel grade. Appendix D gives the specific heat functions for carbon steel, found by differentiating the enthalpy curve from $\mathrm{K}$. Harste ${ }^{[44]}$. Refer to Pehlke $\mathrm{e}^{[45]}$ for the specific heat functions of stainless steel. When the steel temperature is between the solidus and liquidus temperatures, latent heat, $L_{f}$, is evolved using the liquid phase fraction curve found previously. The effective specific heat is then defined as:

$$
C_{p}^{*}=\frac{d H}{d T}=C_{p}-L_{f} \frac{d f_{s}}{d T}
$$

Figure 12 shows the specific heat curve of AISI 1026 carbon steel using the micro-segregation model compared with measured data ${ }^{[4]}$. The curves for other alloys, such as used later, are similar except for within the mushy region. So long as it properly matches the total latent heat, its exact shape has little effect on shell growth or surface temperature.

\section{$D$ Thermal Linear Expansion of Steel}

By default, the thermal linear expansion, TLE, needed for shrinkage and ideal taper calculations is computed as a function of steel density,

$$
T L E=\sqrt[3]{\frac{\rho_{0}}{\rho(T)}}-1
$$


where $\rho_{0}=\rho_{\text {steel }}$. The composition and temperature-dependent steel density function for carbon steel, $\rho(T)$ is taken from measurements tabulated by Harste ${ }^{[4]}$ and is listed in Appendix D. Constant density, $\rho_{\text {steel }}$ is adopted for the heat flow calculations in order to enforce constant mass in the fixed-domain computation.

Alternatively, the user may input a thermal linear expansion coefficient, $\alpha$, so:

$$
T L E=\alpha\left(T-T_{\text {sol }}\right)
$$

This is done for stainless steel, where $\alpha$ is taken from Pehlke ${ }^{[45]}$.

\section{MODEL VALIDATION}

The internal consistency and accuracy of the various components of this model have been verified through extensive comparison with analytical solutions. The accuracy of the 2-D mold heat transfer model at the meniscus region was evaluated by comparison with full threedimensional finite element model computations on separate occasions using ABAQUS ${ }^{[69]}$ and with an in-house code ${ }^{[70]}$. In both cases, the CON1D model predictions matched within the uncertainties associated with mesh refinement of the 3-D model. The fin heat transfer equation was compared with 3-D model computations by $\mathrm{Ho}^{[71]}$ and Langeneckert ${ }^{[60]}$ as already discussed. Its accuracy is acceptable except near thermocouples located in a region of complex heat flow. Its accuracy there can be improved by incorporating an "offset" distance, as discussed elsewhere ${ }^{[26,60]}$. Other obvious checks include ensuring that the temperature predictions match at the transition between at 2-D and 1-D regions, which also indicates when heat flow is 1-D.

The solidification model is verified here through comparison with an analytical solution for 1-D heat conduction with phase change ${ }^{[72]}$. This solution assumes constant shell surface temperature and constant steel properties. Table I lists the constants used in both the analytical solution and CON1D validation case, which are chosen for typical conditions expected in 
practice. The difference between the steel liquidus and solidus temperatures is only $0.1^{\circ} \mathrm{C}$ to approximate the single melting temperature assumed in analytical solution, which is set to the mean of $T_{\text {liq }}$ and $T_{\text {sol }}$ used in CON1D. The pour temperature is set to the liquidus because superheat is neglected in the analytical solution. For the CON1D model, the time step size $\Delta t$ is $0.004 \mathrm{sec}$. and node spacing is $0.5 \mathrm{~mm}$.

Figure 13 compares results from the analytical solution and CON1D model for (a) the temperature distribution through the shell at different times and (b) the growth of shell thickness with time. The results show that the predictions of CON1D model is very accurate, so the same time step and mesh size are used in the following cases.

\section{MODEL CALIBRATION}

Having shown the model to be internally consistent, it cannot be used quantitatively until it is calibrated to match measurements on the specific operating caster of interest. This step is necessary because so many of the inputs to the model are uncertain.

To date, the model has been calibrated to match many different casters, including slabs at BHP LPD in Whyalla, South Australia; LTV Steel in Cleveland, $\mathrm{OH}^{[73]}$, AK Steel in Mansfield, $\mathrm{OH}^{[26]}$, Allegheny Ludlum in Brackenridge, $\mathrm{PA}^{[74]}$, Columbus Stainless Steel in Middleburg ${ }^{[70]}$, South Africa, Siderar in Argentina, and China Steel in Taiwan, ROC; thin slabs at Nucor in Crawfordsville, $\mathrm{IN}^{[75]}$ and POSCO in Seoul, S. Korea ${ }^{[76]}$; blooms at BHP RBPD in Newcastle, New South Wales ${ }^{[7]]}$; and billets at POSCO Pohang in S. Korea ${ }^{[78]}$. In order to calibrate the model, it is simply run several times, using trial and error to find values of the model parameters that allow the model predictions to match all of the known measurements. Those measurements can include the cooling water temperature rise, the time-average temperature of any thermocouples embedded in the mold, the thickness profile of breakout shells, and thickness of 
solidified mold powder layers and slag rims, and the temperature histories of any thermocouples embedded in the strand.

Specifically, adjustments can be made to the velocity of the solid slag layer, the value of the contact resistances down the mold, and even the thermal properties of the mold slag. Other influential input parameters include the average powder consumption rate and the average oscillation mark depth and width.

In a slab caster with properly designed taper, there should not be any air gap due to shrinkage down the center of the wide face. This is because ferrostatic pressure pushes the long, wide, weak shell against the mold to maintain as close a contact as possible. This greatly simplifies model calibration when simulating a slice through the wide face of the mold and shell.

The next sections report on the calibration, validation and results of simulations performed for two sets of conditions given in Tables II and V. Input parameters for the standard case, Table II, were calibrated to match the casting conditions of the $0.225 \mathrm{~m} \times 1.78 \mathrm{~m}$ slabs of low-carbon steel cast at LTV Steel Cleveland, OH, where mold thermocouple temperatures, cooling water temperature rise, and breakout shell measurements were available ${ }^{[71,79]}$. The steel composition is $0.044 \% \mathrm{C}, 0.022 \% \mathrm{Mn}, 0.006 \% \mathrm{~S}, 0.01 \% \mathrm{P}, 0.009 \% \mathrm{Si}$ and $0.049 \% \mathrm{Al}$.

\section{A Mold Cooling Water Temperature Rise}

The first step in model calibration is to match the total heat extracted in the mold, Q, with the measured temperature increase of the mold cooling water. The average rate of heat extracted from the mold per unit surface area, $Q$, is found from:

$$
Q=\frac{V_{c}}{Z_{\text {mold }}} \sum_{\text {mold }} q_{\mathrm{int}} \Delta t
$$

This heat transfer rate should equal the temperature increase of the mold cooling water, $\Delta T_{\text {water }}$, flowing through the "hot" channels, located adjacent to the slab width area: 


$$
\Delta T_{\text {water_hot channels }}=\sum_{\text {mold }} \frac{q_{\text {int }} L_{c h} V_{c} \Delta t}{\rho_{\text {water }} C_{\text {pwater }} V_{\text {water }} w_{c h} d_{c h}}
$$

This equation assumes that the cooling water slots have locally uniform rectangular dimensions, $w_{c h}$ and $d_{c h}$, and spacing, $L_{c h}$. Heat entering the hot face (between two water channels) is assumed to pass straight through the mold to heat the water flowing through the cooling channels.

To compare with the measured water temperature increase, the above prediction is modified as follows to account for missing slots due to bolts or water slots, or slots that are beyond the slab width, so do not participate in heat extraction:

$$
\Delta T_{\text {water_total channels }}=\Delta T_{\text {water_hot channels }} \frac{w_{c h} \cdot d_{c h} \cdot W / L_{c h}}{\text { total channel area }}
$$

Using reported slag properties and consumption rate (Table II), heat flux was calibrated to match the measured temperature rise of $7.1 \mathrm{deg} \mathrm{C}$ by adjusting the solid slag speed ratio, $f_{v}$, to 0.175. The corresponding temperature rise in just the hot channels is predicted to be $7.5 \mathrm{deg} \mathrm{C}$.

\section{$B$ Mold Temperatures}

The next step in calibration of CON1D is to further adjust the model parameters to match the measurements of thermocouples embedded in the walls of the operating casting mold. This step is very constrained, however, as every change that causes a local increase in heat flux must be balanced by a corresponding decrease elsewhere, in order to maintain the balance with the cooling water already achieved.

In this example, Table II, the slag rim shape in region I was chosen to decrease linearly from $0.8 \mathrm{~mm}$ at the meniscus to $0.5 \mathrm{~mm}$ at $15 \mathrm{~mm}$ below the metal level, which is near to the position of peak heat flux. The peak heat flux position should not be confused with the location of peak mold temperature, which is usually about $35 \mathrm{~mm}$ below the heat flux peak $(55 \mathrm{~mm}$ below the 
meniscus in this case). Assuming no air gap in the interface for this wide face simulation, the contact resistances and scale thicknesses are other adjustable input conditions to match the mold thermocouple measurements. Here a $0.02 \mathrm{~mm}$ scale layer was assumed for the top $305 \mathrm{~mm}$, where special designed inserts had been installed to increase the local cooling water velocity, ${ }^{[79]}$ and $0.01 \mathrm{~mm}$ scale for the bottom remainder of the mold. These thicknesses are in accordance with plant observations that the hot region had a thicker scale layer ${ }^{[80]}$.

Figure 14 compares the predicted and measured temperatures at several locations down the LTV mold. The thermocouples were all $18.8 \mathrm{~mm}$ below the mold hot face. The agreement indicates the calibration of the model for these typical casting conditions. This figure also shows the predicted hot face and cold face temperature profiles. The sharp change in temperature is due to a sudden increase in water channel depth, produced by experimental inserts used in the trial ${ }^{[79]}$. Note that the observed scale layer greatly increased the mold temperature, especially in the hot portion that contained the insert. Based on this insight, steps were taken to improve water quality to prevent this scale and improve mold life ${ }^{[79]}$.

\section{Shell Thickness}

Having calibrated the model, the predicted shell thickness profile is compared with measurements down a breakout shell that occurred under very similar castings conditions, as given in Fig.15. Shell thickness is defined in the model by interpolating the position between the liquidus and solidus isotherms with the temperature corresponding to the specified solid fraction, $f_{s}$, according to the phase fraction-temperature relationship in Fig.10. In this sample case, $f_{s}=0.1$, which is the only adjustable parameter remaining for model calibration. This is reasonable as inter-dendritic liquid is held by surface tension during draining of the breakout.

To compare the predicted steady shell thickness with that of a breakout shell, a correction is needed to account for the solidification time that occurred while the liquid metal was draining 
during the breakout. Thus, time in the steady simulation corresponds to distance down the breakout shell according to the relation:

$$
t=\frac{z}{V_{c}}+t_{d}
$$

where the "drainage time" $t_{d}$ is the time for the metal level to drop from the meniscus to the breakout slice of interest, $z$. Drainage time is calculated based on the Bernoulli equation and a mass balance ${ }^{[81]}$ :

$$
t_{d}=\frac{\sqrt{Z_{b}}-\sqrt{Z_{b}-z}}{C_{D} \frac{\pi d_{b}^{2}}{4 N W} \sqrt{\frac{g}{2}}}
$$

where the drainage coefficient $C_{D}=1$. For the present case, the position of the breakout hole from the meniscus, $Z_{b}=1.524 \mathrm{~m}$; slab thickness, $N=0.225 \mathrm{~m}$; slab width, $W=1.78 \mathrm{~m}$. Assuming that steel flow to the mold was shut off simultaneously with the metal level starting to drop below the meniscus, and the breakout hole diameter $d_{b}$ began at $50 \mathrm{~mm}$ and linearly grew to $90 \mathrm{~mm}$ by the time all liquid steel had drained, a transient shell profile can be calculated. Figure 15 gives the predicted shell thickness at both steady state and transient conditions, compared with the breakout shell measurements. The generally close match with the transient predictions tends to validate the model. The underpredicted shell thickness near the meniscus is likely due to a short interval of increased liquid flow into the mold after the breakout started and before level control and flow were shut off. This would have allowed the liquid level to move downward with the top of the breakout shell for a short time interval (not included in the model), thus providing additional solidification time at the very top of the breakout shell. This effect is commonly observed in breakout shells.

Growth of the shell naturally depends on both the interfacial and superheat fluxes. The superheat distribution is important to the narrow face, as Fig.2 shows that the two curves are of 
the same magnitude low in the mold where the hot molten steel jet impinges against the solidifying shell. Figure 15 shows the shell thinning of narrow face due to this jet impingement effect.

Variation in the superheat flux is critical to shell growth down the narrow face and off-corner regions, where problems such as inadequate taper sometimes produce significant air gap(s). Together, the large superheat combined with decreased heat transfer across the interfacial gap can reduce shell growth. This was the subject of a significant study using the model, which was reported elsewhere ${ }^{[82]}$.

\section{Powder Layer Thickness}

The model predicts the thickness and velocity profiles expected in the powder layers in the interfacial gap. For example, Fig.16 shows the solid and liquid slag layer thickness profiles expected for the standard conditions investigated here (Table II). It shows that the liquid slag layer runs out at $380 \mathrm{~mm}$ below the meniscus, where the liquid slag layer/steel shell interface temperature $T_{s}$ ' drops below the slag solidification temperature of $1045^{\circ} \mathrm{C}$ as shown in Fig.17. The total slag thickness continues to increase while there is still liquid coming from the oscillation marks. This is indicated in Fig.17, where the shell surface temperature at the oscillation mark roots, $T_{s}$, still exceeds $1045^{\circ} \mathrm{C}$ at mold exit. Although no reliable slag samples were obtained from this caster, these slag thickness predictions of 0.5 to $1.5 \mathrm{~mm}$ are consistent with samples measured at similar plants ${ }^{[47,76]}$.

\section{E Shell Surface Temperature}

Typical model predictions of the surface temperature in the mold are shown in Fig.17 for standard conditions. When liquid slag layer runs out at $380 \mathrm{~mm}$ below the meniscus (Fig.16), the liquid entrapped in oscillation marks flows out and air fills in, which increases the resistance of 
oscillation mark, so the temperature difference between oscillation marks root and peak increases also, as shown in Fig.17.

After exiting the mold, the slab surface quickly reheats, and then it fluctuates greatly as it travels through the spray zones. Heat is extracted rapidly during contact with the support rolls and when passing the impingement zone of the cooling water from the spray nozzles, which each cause great temporary drops in surface temperature.

Lacking accurate spray and roll contact heat transfer coefficients, calibration of temperature predictions below the mold can be calibrated by adjusting the model parameters $f_{\text {roll }}$ and spray coefficients (Table III) to match measurements such as roll cooling water heat extraction rate, and thermocouple temperatures embedded in the strand. An example of such calibration is shown in Fig. 18 for casting conditions measured at China Steel \#1 slab caster in Taiwan, ROC, given in Tables III and IV. The temperature measurements were achieved by feeding a block containing several thermocouples into the mold just before "tail-out" at the end of casting. The thermocouple tips extending through the bottom of the block were soon frozen into the strand. The last several meters of steel before the end of the cast ensured that the recorded temperature histories would be typical, while allowing the insulated tube of thermocouple wires extending from the top of the block to follow the strand through the caster with minimal damage. The distance of each thermocouple from the surface was measured after sectioning the final product.

Internal temperature histories measured at three places beneath the surface are included in Fig. 18. Both surface thermocouples needed about $500 \mathrm{~mm}$ to heat up to their surrounding shell temperatures, and later suffered from internal debonding, so their results are reliable only between 500 and $3000 \mathrm{~mm}$. The centerline thermocouple needed almost $2 \mathrm{~m}$ to heat up and appears to be accurate within $10^{\circ} \mathrm{C}$. Both the internal temperatures and the amplitude of their wiggles are roughly matched, indicating the degree of calibration. Temperature fluctuations at 
the thermocouple location are quite small, compared with the surface, which varies over $100^{\circ} \mathrm{C}$ over a single roll pitch. Near the top of the caster, the greatest surface temperature drop occurs beneath each spray jet, while a tiny dip occurs at each small region of direct contact with a support roll. Lower in the caster, the relative size of the dips becomes closer, with deep sharp drops caused by the high local heat extraction rate during roll contact under high ferrostatic pressure

Optical pyrometers are also useful for model calibration ${ }^{[61]}$, but are adversely affected by intermittent changes in surface scale emissivity and steam density from evaporating spray water, so are most accurate when located below the spray chamber. Attaching thermocouples directly to the strand surface is another difficult experimental method that can be used for model calibration $^{[19]}$.

\section{SAMPLE APPLICATIONS}

The calibrated model has many applications for both design and operation of continuous casting machines. Firstly, it can help to investigate the effect of various process conditions on the fundamentals of mold heat transfer. Most parameters, such as oscillation practice, powder type, casting speed, and steel grade, affect heat transfer in several different ways, which can only be isolated and quantified independently using a model.

The model can make predictions of potential quality problems, which have more relevance in practice than simple heat transfer. For example, a warning of possible boiling in the cooling water channels is issued when the mold surface temperature exceeds the pressure-dependent water boiling temperature. The model is currently being extended to make other warnings such as breakout danger from excessive shell thinning at mold exit, solid slag-layer fracture from excessive mold friction and the accompanying heat flux variations, and crack formation. Finally, the model should predict optimum casting conditions to avoid problems, whenever possible. 
Initial features of the model toward this goal include a prediction of ideal mold taper. Together with other resources, CON1D is a powerful tool to investigate the cause and prevention of quality problems and to investigate potential design and operation improvements prior to costly experimental implementation.

\section{A Parametric Studies: Effect of Casting Speed}

As an example to illustrate the use of the model to understand fundamental phenomena in the mold, simulations were performed to investigate just two of the many interdependent parameters: casting speed and mold powder consumption. It is well known that increasing casting speed causes changes to other parameters, such as decreased mold powder consumption rate and shallower oscillation marks. To investigate the effect of increasing casting speed in a typical real caster, oscillation frequency was increased proportionally with speed, according to plant practice, and oscillation mark depth was decreased, such that the negative strip ratio and the lubrication consumption rate remained constant. The "lubrication consumption rate", $Q_{l u b}$ is a useful concept for comparing different powder consumption rates. It is introduced here as the rate of slag consumption neglecting the slag carried in the oscillation marks:

$$
Q_{\text {lub }}=Q_{\text {slag }}-Q_{\text {osc }}
$$

Oscillation marks filled with slag and moving at the casting speed consume slag at the following rate, $Q_{\text {osc }}$ :

$$
Q_{\text {osc }}=\frac{0.5 \rho_{\text {slag }} \cdot d_{\text {mark }} \cdot w_{\text {mark }}}{L_{\text {pitch }}}
$$

Thus, the total consumption rate of slag, $Q_{\text {slag, }}$ depends greatly on the oscillation mark shape, while lubrication depends mainly on $Q_{l u b}$, and mold heat transfer depends on both.

To investigate the effect of mold powder consumption rate, an intermediate case of standard (low) casting speed with decreased consumption rate is also included. The three cases in this 
study are listed in Table V, with other conditions given in Table II. The lubrication consumption rate, $Q_{l u b}$ for all 3 cases is $0.4 \mathrm{~kg} / \mathrm{m}^{2}$.

Figure 19 presents the heat flux profiles down the mold wide face calculated for all three cases. Decreasing the powder consumption rate at constant casting speed (Case 2) is seen to increase heat flux in the top portion of the mold, relative to standard conditions (Case 1). This is because the average thickness of the slag layers decreases, thus lowering the interfacial resistance. This effect diminishes with distance down the mold, (as the importance of interfacial resistance to heat transfer decreases relative to that from increasing steel shell thickness).

The practical case of increasing casting speed and simultaneously decreasing total powder consumption rate and oscillation mark depth (Case 3) also increases heat flux toward the bottom of the mold. This is due to the lower thermal resistance of a thinner steel shell produced with less solidification time, which becomes increasingly important with distance down the mold. The net result of increasing casting speed (comparing Case 3 with Case 1) is to increase heat flux almost uniformly down the mold. This is reflected in uniformly higher mold temperatures, as seen in the model predictions in Fig.20. This prediction also matches mold thermocouple measurements obtained for Case 3 conditions, as included in Fig 20. The higher speed leads to a thinner steel shell and higher steel surface temperature so the liquid slag layer persists further down the mold, as shown in Figs.21, 22 and 23 respectively. But the higher heat flux for higher casting speed also lowers the shell surface temperature, which partially cancels the effect of higher temperature due to thinner shell. For these cases, the surface temperatures at the oscillation marks root near mold exit are almost the same, as shown in Figs 22 and 24. Figure 24 compares the shell temperature profiles at mold exit.

The model is suited to many further fundamental parametric studies of this kind. For example, steel grade affects the average oscillation mark size, powder consumption rate, air gap 
size due to thermal contraction (narrow face), and steel strength. Mold powder properties and oscillation practice have similar interdependent effects. The effect of oscillation mark depth, for example, is quantified in a model application reported elsewhere ${ }^{[73]}$.

\section{B Boiling Prediction}

The model issues a warning that boiling is possible, if the mold cold face temperature exceeds the boiling temperature for the given operating pressure in the cooling water channels ${ }^{[83]}$ :

$$
\text { Boiling if : } T_{\text {cold }}\left({ }^{\circ} C\right)>100(P(M P a) / 0.10135)^{0.27}
$$

Boiling in the water channels changes the rate of heat removal and causes temperature fluctuations that together pose a serious potential quality problem. Figure 14 shows that boiling is indeed possible for the conditions investigated here. This is due to the $0.02 \mathrm{~mm}$ thick layer of scale on the mold cold face near the meniscus, which raises the mold face temperature $\sim 70^{\circ} \mathrm{C}$. On the other hand, adding a $0.5 \mathrm{~mm}$ thick protective Ni coating to the hot face is predicted to have only a minimal effect on heat flux and cold face temperature. The CON1D model is ideal for quantifying effects such as these.

\section{Breakout Analysis}

The model can be used to help understand how a breakout may have arisen. Sticker breakouts are easily identified by their characteristic effect on mold thermocouple histories. Other breakouts, such as those caused by inadequate taper, can be more difficult to identify. For example, the model could be used to determine whether a given narrow-face breakout was more likely caused by excessive superheat resulting from a clogged nozzle, or from insufficient mold taper, causing an excessive gap. Either condition could produce a narrow-face shell that is too hot and thin to have the hot strength needed to avoid rupture. Further calibration may allow the 
model to accurately warn of a potential breakout when shell growth is predicted to fall below a critical value. Initial work towards this end is reported elsewhere ${ }^{[30]}$.

\section{Lubrication Prediction}

The model is being extended to predict the consequences of interfacial heat transfer on mold friction and steel quality ${ }^{[55]}$. If the mold slag, which fills most of the gap, is allowed to cool completely below its crystallization temperature, then it becomes viscous and is less able to lubricate the strand. This may increase mold friction, cause the solid slag layer to fracture, and lead to transient temperature changes, making problems such as surface cracks more likely. Figure 16 suggests that this might occur below $400 \mathrm{~mm}$, for the present conditions.

\section{E Crack Formation Analysis}

As with previous continuous casting models, CON1D can be used to locate where defects are formed. For example, by accurately predicting the shell thickness exiting the mold, the model can identify whether a subsurface crack formed in or below the mold. This can be difficult to tell, particularly near the narrow face, where shell growth is slower. Here, a crack forming below the mold might appear to have formed in the mold without an accurate calculation of shell growth that incorporates superheat delivery. The model can also simulate phenomena below the mold, such as reheating of the shell surface, which can lead to surface cracks. Sub-mold bulging and crack formation requires accurate temperature variation between rolls, so the model is useful for designing spray water-cooling systems.

\section{F Calculation of Ideal Mold Taper}

The narrow-face of the mold should be tapered to match the shrinkage of steel shell, which is cooling against the wide face. Previous work has determined that this shrinkage depends mainly on the surface temperature of the shell and the steel grade ${ }^{[12]}$. The model predicts ideal average 
taper, by dividing the thermal strain, $\varepsilon$, by distance down the mold (instantaneous taper) or by the mold length (total taper per $\mathrm{m}$ ). Thermal shrinkage strain is estimated here in two different ways, firstly $\varepsilon_{t h 1}$, by:

$$
\varepsilon_{t h 1}=T L E\left(T_{s o l}\right)-T L E\left(T_{s}\right)
$$

Another method to calculate shrinkage was developed by Dippenaar ${ }^{[34,84]}$. The strain $\varepsilon_{t h 2}$, is computed by summing the average thermal linear expansion of the solid portion of the shell between each pair of consecutive time steps:

$$
\varepsilon_{t h 2}=\sum_{t=0}^{t}\left(\left(\frac{1}{i}\right)^{\text {solid nodes }} \sum_{i=1}^{T}\left(T L E\left(T_{i}^{t}\right)-T L E\left(T_{i}^{t+\Delta t}\right)\right)\right)
$$

Here, TLE is the thermal linear expansion function for the given steel grade, calculated from weighted averages of the phases present.

For the sample cases, the higher speed causes a hotter shell with less shrinkage, shown in Fig. 25, so needs slightly less narrow face mold taper. The shrinkage $\varepsilon_{t h l}$, based on surface temperature only, is generally less than $\varepsilon_{t h 2}$, and is almost independent of casting speed, due to the cancellation effect discussed in Section VI-A. With a linear taper, the narrow-face shell attempts to shrink away from the upper portion of the mold, while it pushes against the lower portion of the mold. To match the shrinkage, it is clear that taper should be increased high in the mold and decreased lower down. Mold distortion, viscoplastic creep of the steel, and other factors should also be taken into account when designing a non-linear mold taper. These calculations require sophisticated thermal-stress models, to calculate temperatures, stresses, and shrinkage, including the formation of an air gap near the corners, and its effect on heat flow across the mold/shell interface. The calibrated CON1D model is currently being used to provide calibrated heat transfer data to these models to evaluate and improve taper optimization. 


\section{$G$ Future Applications}

The model is based on conservation laws that must hold, regardless of the complex phenomena present in the caster. However, there are many more unknowns than equations. Thus, the model requires extensive calibration, which include the values of many parameters not currently known. Preferably, some of the required input data should be predicted, such as powder consumption rate and oscillation mark size.

Much further work is needed before the model can realize its full potential as a predictive tool for design, improvement, and control of continuous casting operations. For example, the model simulates only time-averaged behavior, while in reality, many phenomena, especially involving the slag layer, vary greatly during each oscillation cycle. This requires a detailed, transient treatment. When and how the solid slag layer slides along the mold wall, the accompanying friction forces, and if and where the solid slag fractures are other important issues. Below the mold, fundamental measurements of spray-zone heat transfer are needed. This work will require advanced 3-D model strand calculations, in addition to extensive calibration.

\section{CONCLUSIONS}

A simple but comprehensive heat flow model of the continuous slab-casting mold, gap, and shell has been developed. It simulates 1-D solidification of the steel shell, and features the dissipation of superheat, movement of the solid and liquid slag layers in the interfacial gap, and 2-D heat conduction within the copper mold wall. The model accounts for the effects of oscillation marks on both heat transfer and powder consumption. It also accounts for variations in water slot geometry and steel grade. It is user-friendly and runs quickly on a personal computer. It has been validated through numerical comparisons and calibrated with measurements on operating casters, including cooling water temperature rise, mold thermocouple temperatures, breakout shell thickness, slag layer thickness, and thermocouples 
embedded in the steel shell. In addition to heat transfer, the model predicts thickness of the solidified slag layers, ideal mold taper, and potential quality problems such as complete slag solidification, and boiling in the water channels. It has many potential applications.

\section{ACKNOWLEDGMENTS}

The authors wish to thank former students Bryant Ho, Guowei Li, and Ying Shang for their work on early versions of the CON1D program and to the Continuous Casting Consortium at the University of Illinois and the National Science Foundation (Grants \# MSS-89567195 and DMI01-15486) for funding which made this work possible. Some 3D computations for validation

were performed at the National Center for Supercomputing Applications at UIUC. Special thanks go to Bill Emling and others at LTV Steel and to Kuan-Ju Lin and others at China Steel for collecting the operating data and experimental measurements used in model validation. 


\section{NOMENCLATURE}

\begin{tabular}{|c|c|c|}
\hline$C p$ & specific heat $(\mathrm{J} / \mathrm{kgK})$ & steel liquid temperature $\left({ }^{\circ} \mathrm{C}\right)$ \\
\hline$d$ & depth/thickness (m) & steel solidus temperature $\left({ }^{\circ} \mathrm{C}\right)$ \\
\hline$d_{b}$ & diameter of the breakout hole (m) & steel shell surface temperature (at oscillation \\
\hline$d_{o s c}$ & volume-averaged osc.-mark depth (mm) & mark root $)\left({ }^{\circ} \mathrm{C}\right)$ \\
\hline freq & mold oscillation frequency $(\mathrm{cpm})$ & liquid slag layer hot-side temperature $\left({ }^{\circ} \mathrm{C}\right)$ \\
\hline$f_{\text {roll }}$ & fraction of heat flow per spray zone going to & cooling water temperature rise $\left({ }^{\circ} \mathrm{C}\right)$ \\
\hline & roll (-) & thermal linear expansion $(-)$ \\
\hline$f_{s}$ & solid steel fraction (-) & casting speed $(\mathrm{m} / \mathrm{s})$ \\
\hline$f_{v}$ & empirical solid slag layer speed factor (-) & width (m) \\
\hline$g$ & gravity $\left(9.81 \mathrm{~m} / \mathrm{s}^{2}\right)$ & slab width (m) \\
\hline$h$ & heat transfer coefficient $\left(\mathrm{W} / \mathrm{m}^{2} \mathrm{~K}\right)$ & shell thickness direction $(\mathrm{m})$ \\
\hline$h_{\text {conv }}$ & natural convection $h$ in spray zones & casting-dir, distance below meniscus (m) \\
\hline & $\left(\mathrm{W} / \mathrm{m}^{2} \mathrm{~K}\right)$ & working mold length (m) \\
\hline$h_{\text {rad_spray }}$ & radiation $h$ in spray zones $\left(\mathrm{W} / \mathrm{m}^{2} \mathrm{~K}\right)$ & thermal linear expansion coefficient $\left(\mathrm{K}^{-1}\right)$ \\
\hline$h_{\text {rad }}$ & radiation $h$ in slag layers $\left(\mathrm{W} / \mathrm{m}^{2} \mathrm{~K}\right)$ & Stefan Boltzman constant \\
\hline$k$ & thermal conductivity $(\mathrm{W} / \mathrm{mK})$ & $\left(5.67 \times 10^{-8} \mathrm{~W} / \mathrm{m}^{2} \mathrm{~K}^{4}\right)$ \\
\hline $\begin{array}{l}L^{\prime} \\
L_{f}\end{array}$ & $\begin{array}{l}\text { length }(\mathrm{m}) \\
\text { latent heat of steel }(\mathrm{kJ} / \mathrm{kg})\end{array}$ & surface emissivities (-) \\
\hline $\begin{array}{l}L_{f} \\
L_{\text {pitch }}\end{array}$ & $\begin{array}{l}\text { latent heat of steel }(\mathrm{KJ} / \mathrm{kg}) \\
\text { distance between successive oscillation }\end{array}$ & thermal strain of steel shell $(\%)$ \\
\hline & marks (m) & density $\left(\mathrm{kg} / \mathrm{m}^{3}\right)$ \\
\hline$n$ & $\begin{array}{l}\text { exponent for temperature dependence of } \\
\text { slag viscosity (-) }\end{array}$ & viscosity $(\mathrm{Pa} \mathrm{s})$ \\
\hline$N$ & slab thickness $(\mathrm{m})$ & Subscripts: \\
\hline$P r_{\text {waterw }}$ & Prandtl \# of water at mold cold face & steel steel slab \\
\hline & temperature $\left(C_{p} \mu / k\right)$ & $\alpha, \delta, \gamma, l \quad \alpha-\mathrm{Fe}, \delta$-Fe, $\gamma-\mathrm{Fe}$, liquid steel phases \\
\hline$Q$ & average mold heat flux $\left(\mathrm{kW} / \mathrm{m}^{2}\right)$ & mold $\quad$ copper mold \\
\hline$Q_{\text {slag }}$ & mold slag consumption $\left(\mathrm{kg} / \mathrm{m}^{2}\right)$ & mold coating layer \\
\hline$Q_{\text {water }}$ & water flow rate in spray zones $\left(1 / \mathrm{m}^{2} \mathrm{~s}\right)$ & cooling water \\
\hline$q_{\text {int }}$ & shell/mold interface heat flux $\left(\mathrm{kW} / \mathrm{m}^{2}\right)$ & cooling water channel in mold \\
\hline$q_{s h}$ & superheat flux $\left(\mathrm{kW} / \mathrm{m}^{2}\right)$ & scale layer in mold cooling channel \\
\hline $\operatorname{Re}_{\text {waterf }}$ & Reynolds \# at average of mold cold face and & oscillation mark \\
\hline & cooling water temperatures $(D V \rho / \mu)$ & effective oscillation mark (based on heat \\
\hline$r_{\text {contact }}$ & slag/mold contact resistance $\left(\mathrm{m}^{2} \mathrm{~K} / \mathrm{W}\right)$ & air gap \\
\hline$t$ & time (s) & sholl/mold ran \\
\hline$t_{d}$ & drainage time (s) & shell/mold gap \\
\hline$T$ & temperature $\left({ }^{\circ} \mathrm{C}\right)$ & slag $\quad$ mold slag \\
\hline$T_{\text {fsol }}$ & mold slag solidification temperature $\left({ }^{\circ} \mathrm{C}\right)$ & solid, liquid solid slag layer, liquid slag layer \\
\hline$T_{\text {hotc }}$ & mold copper hot face temperature $\left({ }^{\circ} \mathrm{C}\right)$ & spray nozzle below mold \\
\hline$T_{\text {mold }}$ & mold hot face temperature with coating $\left({ }^{\circ} \mathrm{C}\right)$ & \\
\hline
\end{tabular}




\section{REFERENCES}

1. F.M. Najjar, B.G. Thomas and D.E. Hershey: "Numerical study of steady turbulent flow through bifurcated nozzles in continuous casting", Metall. Mater. Trans. B (USA), 1995, vol. 26B (4), pp. 749-65.

2. $\quad$ K.C. Mills: "The Performance of Casting Powders", Steel Technol. Int., 1994, pp. 161-66.

3. R.J. O'Malley: An Examination of Mold Flux Film Structures and Mold Gap Behavior Using Mold Thermal Monitoring and Petrographic Analysis at Armco's Mansfield Operations, Report.

4. R.J. O'Malley: "Observations of various steady state and dynamic thermal behaviors in a continuous casting mold", 82nd Steelmaking Conference, (Chicago, IL, USA), 1999, vol. 82, pp. 13-33.

5. A. Yamauchi, K. Sorimachi, T. Sakuraya and T. Fujii: "Heat Transfer Between Mold and Strand Through Mold Flux Film in Continuous Casting of Steel", ISIJ International (Japan), 1993, vol. 33 (1), pp. 140-47.

6. J. Cho, H. Shibata, T. Emi and M. Suzuki: "Thermal resistance at the interface between mold flux film and mold for continuous casting of steels", ISIJ International (Japan), 1998, vol. 38 (5), pp. 440-46.

7. M.S. Bhamra, M.G. Charlesworth, S. Wong, D. Sawyers-Villers and A.W. Cramb: "Crystallization of fluxes under varying cooling rates", 54th Electric Furnace Conference, (Dallas, Texas, USA), 1996, vol. 54, pp. 551-64.

8. C. Orrling, A.W. Cramb, A. Tilliander and Y. Kashiwaya: "Observations of the melting and solidification behavior of mold slags", Iron and Steelmaker (USA), 2000, vol. 27 (1), pp. 53-63.

9. Y. Kashiwaya, C.E. Cicutti and A.W. Cramb: "An investigation of the crystallization of a continuous casting mold slag using the single hot thermocouple technique", ISIJ International (Japan), 1998, vol. 38 (4), pp. 357-65.

10. B.G. Thomas, G. Li, A. Moitra and D. Habing: "Analysis of Thermal and Mechanical Behavior of Copper Molds during Continuous Casting of Steel Slabs", 80th Steelmaking Conference, (Chicago, IL), 1997, vol. 80, pp. 183-201.

11. X. Huang, B.G. Thomas and F.M. Najjar: "Modeling Superheat Removal during Continuous Casting of Steel Slabs", Metall. Mater. Trans. B (USA), 1992, vol. 23B (6), pp. 339-56.

12. A. Moitra and B.G. Thomas: "Application of a Thermo-Mechanical Finite Element Model of Steel Shell Behavior in the Continuous Slab Casting Mold", 76th Steelmaking Conference, (Dallas, TX), 1993, vol. 76, pp. 657-67.

13. B.G. Thomas: "Mathematical Modeling of the Continuous Slab Casting Mold: a State of the Art Review", 1991 Steelmaking Conference, 1991, pp. 69-82.

14. B.G. Thomas and L. Zhang: "Mathematical modeling of fluid flow in continuous casting", ISIJ International (Japan), 2001, vol. 41 (10), pp. 1181-93.

15. B.G. Thomas: "Modeling of the continuous casting of steel - past, present and future", Metall. Mater. Trans. B (USA), 2002, vol. 33B (6), pp. 795-812.

16. E.A. Mizikar: "Mathematical Heat Transfer Model for Solidification of continuosly Cast Steel Slabs", AIME MET SOC TRANS, 1967, vol. 239 (11), pp. 1747-58.

17. J.E. Lait, J.K. Brimacombe and F. Weinberg: "Mathematical Modelling of Heat Flow in the Continuous Casting of Steel", ironmaking and Steelmaking, 1974, vol. 1 (2), pp. 90-97.

18. E.A. Upton, T.R.S. Rao, P.H. Dauby and R.C. Knechtges: "Physical Metallurgy and Mathematical Modeling as Tools for Continuous Casting Optimization at LTV Steel", Iron Steelmaker, 1988, vol. 15 (5), pp. 51-57.

19. R. Davies, N. Blake and P. Campbell: "Solidification Modelling--an Aid to Continuous Casting", 4th International Conference Continuous Casting. Preprints. Vol. 2, ,, (Brussels, Belgium), 1988, vol. 2, pp. $645-54$.

20. R.B. Mahapatra, J.K. Brimacombe, I.V. Samarasekera, N. Walker, E.A. Paterson and J.D. Young: "Mold Behavior and Its Influence on Quality in the Continuous Casting of Steel Slabs. I. Industrial Trials, Mold Temperature Measurements, and Mathematical Modeling", Metall. Trans. B, 1991, vol. 22B (6), pp. 86174.

21. J.K. Brimacombe: "Design of Continuous Casting Machine Based on a Heat Flow Analysis: State-of-theArt Review", Canadian Metallurgical Quarterly, 1976, vol. 15 (2), pp. 163-75. 
22. M.R. Aboutalebi, R.I.L. Guthrie and M. Hasan: "Thermal modelling and stress analysis in the continuous casting of arbitrary sections", Steel Research, 1994, vol. 65 (6), pp. 225-33.

23. F. Wimmer, H. Thone and B. Lindorfer: "Thermomechanically-coupled analysis of the steel solidification process in the continuous casting mold as a basis for the development of a high speed casting mold", Bergund Huttenmannische Monatshefte (Austria), 1996, vol. 141 (5), pp. 185-91.

24. H. Nam, H.S. Park and J.K. Yoon: "Numerical analysis of fluid flow and heat transfer in the funnel type mold of a thin slab caster", ISIJ International (Japan), 2000, vol. 40 (9), pp. 886-92.

25. S.K. Choudhary and D. Mazumdar: "Mathematical modelling of transport phenomena in continuous casting of steel", ISIJ International (Japan), 1994, vol. 34 (7), pp. 584-92.

26. B.G. Thomas, R.J. O'malley, T. Shi, Y. Meng, D. Creech and D. Stone: "Validation of fluid flow and solidification simulation of a continuous thin-slab caster", Modeling of Casting, Welding and Advanced Solidification Process IX, (Aachen, Germany), 2000, pp. 769-76.

27. J.E. Lee, T.J. Yeo, K.H. Oh, J.K. Yoon and U.S. Yoon: "Prediction of cracks in continuously cast steel beam blank through fully coupled analysis of fluid flow, heat transfer, and deformation behavior of a solidifying shell", Metallurgical and Materials Transactions A (USA), 2000, vol. 31A (1), pp. 225-37A.

28. C. Ohler, H.J. Odenthal, H. Pfeifer and I. Lemanowicz: "Numerical simulation of the fluid flow and solidification phenomena in a thin slab caster", Stahl und Eisen (Germany), 2002, vol. 122 (3), pp. 55-63.

29. B.G. Thomas, W.R. Storkman and A. Moitra: "Optimizing Taper in Continuous Slab Casting Molds Using Mathematical Models", IISC. The Sixth International Iron and Steel Congress, (Nagoya, Japan), 1990, vol. Vol 3, Steelmaking I, pp. 348-55.

30. C. Li and B.G. Thomas: "Analysis of the potential productivity of continuous cast molds", The Brimacombe Memorial Symposium, (Vancouver, British Columbia, Canada), 2000, pp. 595-611.

31. B.G. Thomas, A. Moitra and R. McDavid: "Simulation of longitudinal off-corner depressions in continuously cast steel slabs", Iron and Steelmaker (USA), 1996, vol. 23 (4), pp. 57-70.

32. J.K. Park, I.V. Samarasekera, B.G. Thomas and U.S. Yoon: "Analysis of thermal and mechanical behavior of copper mould during thin slab casting", 83rd Steelmaking Conference, (Pittsburgh, PA, USA), 2000, vol. 83, pp. 9-21.

33. C.A.M. Pinheiro, I.V. Samarasekera and B.N. Walker: "Mould heat transfer and continously cast billet quality with mould flux lubrication", Ironmaking and Steelmaking (UK), 2000, vol. 27 (1), pp. 37-54.

34. S. Chandra, J.K. Brimacombe and I.V. Samarasekera: "Mould-Strand Interaction in Continuous Casting of Steel Billets. III. Mould Heat Transfer and Taper", Ironmaking and Steelmaking (UK), 1993, vol. 20 (2), pp. 104-12.

35. F. Wimmer, H. Thone and B. Lindorfer: "Thermomechanically-coupled analysis of the steel solidification process as a basis for the development of a high speed billet casting mold", The International Conference on Modelling and Simulation in Metallurgical Engineering and Materials Science, (Beijing, China), 1996, pp. 366-71.

36. N. Tiedje and E.W. Langer: "Metallographic Examination of Breakouts From a Continuous Billet Caster", Scandinavian Journal of Metallurgy (Denmark), 1992, vol. 21 (5), pp. 211-17.

37. R. Bommaraju and E. Saad: "Mathematical Modelling of Lubrication Capacity of Mold Fluxes", 73th Steelmaking Conference, (Detroit, Michigan, USA), 1990, vol. 73, pp. 281-96.

38. J.A. DiLellio and G.W. Young: "Asymptotic model of the mold region in a continuous steel caster", Metallurgical and Materials Transactions B: Process Metallurgy and Materials Processing Science, 1995, vol. 26B (6), pp. 1225-441.

39. J.F. Chavez, A. Celaya, M.A. Barron and R.D. Morales: "Heat transfer in mold flux-layers during slab continuous casting", Seventy Ninth Conference of the Steelmaking Division of the Iron and Steel Society, (Pittsburgh, Pennsylvania, USA), 1996, vol. 79, pp. 321-29.

40. G.J.W. Kor: "An Analysis of the Fluid Flow of Liquid Mold Powder in the Space Between the CC Mold and the Steel Shell", Continuous Casting of Steel, 2nd Process Technology Conf., (Chicago, Ill., USA), 1981, vol. 2, pp. 124-32.

41. K. Nakajima: "Heat transfer and lubrication behavior in mold at high-speed continuous casting of steel slabs", Curr. Adv. Mater. Process., 1992, vol. 5 (4), pp. 1221-24. 
42. T. Cimarelli: "Mould powder influence on continuous casting operations and on slabs surface quality", Metallurgia Italiana (Italy), 1997, vol. 89 (9), pp. 31-37.

43. D.R. Bland: "Flux and the Continuous Casting of Steel", IMA Journal of Applied Mathematics, 1984, vol. 32, pp. 89-112.

44. K. Harste: Investigation of the shinkage and the origin of mechanical tension during the solidification and successive cooling of cylindrical bars of $\mathrm{Fe}-\mathrm{C}$ alloys, $\mathrm{PhD}$ Dissertation Thesis, Technical University of Clausthal, 1989.

45. R.D. Pehlke, A. Jeyarajan and H. Wada: Summary of Thermal Properties for Casting Alloys and Mold Materials, Michigan Univ., Report No. NSFMEA82028, 1982.

46. H. Shibata, K. Kondo and M. Suzuki: "Thermal Resistance between Solidifying Steel Shell and Continuous Casting Mold with Intervening Flux Film", ISIJ Int. (Japan), 1996, vol. 35 (Suppl.), pp. S179S82.

47. B. Ho: Characterization of Interfacial Heat Transfer in the Continuous Slab Casting Process, Master Thesis, UIUC, 1992.

48. K. Ichikawa, A. Morita and Y. kawabe: "Behavior of Powder Slag Film and Influence of Powder Slag on Mold Heat Transfer Rate", Shinagawa Technical Report, 1993, vol. 36, pp. 99-107.

49. K. Watanabe, M. Suzuki, K. Murakami, H. Kondo, A. Miyamoto and T. Shiomi: "The effect of mold powder crystallization on heat transfer in continuous casting mold", NKK Technical Review (Japan), 1997, vol. 77 , pp. $20-26$.

50. R. Taylor and K.C. Mills: "Physical Properties of Casting Powders III: Thermal Conductivities of Casting Powders", Ironmaking and Steelmaking (UK), 1988, vol. 15 (4), pp. 187-94.

51. A.C. Mikrovas, S.A. Argyropoulos and I.D. Sommerville: "Measurements of the Effective Thermal Conductivity of Liquid Slags", Iron and Steelmaker (USA), 1991, vol. 18 (12), pp. 51-61.

52. M.S. Jenkins: "Characterization of heat transfer in a continuous casting mold", in Continuous Casting, vol. Volume 9: Initial Solidification and Strand Surface Quality of Peritectic Steels (USA), I.a.S. Society/AIME, ed., Iron and Steel Society/AIME, 410 Commonwealth Drive, Warrendale, PA 150867528, USA, 1997, pp. 239-44.

53. M.D. Lanyi and C.J. Rosa: "Viscosity of Casting Fluxes Used During Continuous Casting of Steel", Metall. Trans. B, 1981, vol. 12B (2), pp. 287-98.

54. D. Larson: "Criteria for Selecting Mold Powders to Optimize Continuous Cast Steel Quality", Industrial Heating, 1986, vol. 53 (4), pp. 16-17.

55. Y. Meng and B.G. Thomas: "Modeling Transient Slag Layer Phenomena in the Shell/Mold Gap in Continuous Casting of Steel", Metall. Mater. Trans. B (USA), 2003, (submitted).

56. H.S. Carslaw and J.C. Jaeger: Conduction of heat in solids, 2nd ed., Oxford University Press, 1986.

57. L.C. Burmesiter: Convective Heat Transfer, 2 ed., Wiley, New York, 1993, p. 484.

58. C.A. Sleicher and M.W. Rouse: "A convenient correlation for heat transfer to constant and variable property fluids in turbulent pipe flow", International Journal of Heat \& Mass Transfer, 1975, vol. 18 (5), pp. 677-83.

59. F.W. Dittus and L.M.K. Boelter: "Heat Transfer in Automobile Radiators of the Tubular Type", University of California Publications in Engineering, 1930, (2), pp. 443-61.

60. M.M. Langeneckert: Influence of mold geometry on heat transfer, thermocouple and mold temperatures in the continuous casting of steel slabs, Master Thesis, University of Illinois, 2001.

61. J.K. Brimacombe, P.K. Agarwal, S. Hibbins, B. Prabhaker and L.A. Baptista: "Spray Cooling in the Continuous Casting of Steel", vol. 2, Continuous Casting1984, pp. 109-23.

62. T. Nozaki: "A Secondary Cooling Pattern for Preventing Surfcace Cracks of Continuous Casting Slab", Trans. ISIJ, 1978, vol. 18, pp. 330-38.

63. R.A. Hardin, H. Shen and C. Beckermann: "Heat Transfer Modeling of Continuous Steel Slab Caster Using Realistic Spray Patterns", Modelling of Casting, Welding and Advanced Solidification Processes IX, 2000.

64. R.D. Pehlke: "Computer Simulation of Continuous Casting", Enginneering Summer Conference: Continuous Casting of Steel, 1980, pp. Section VII, 1-17. 
65. V.R. Voller, C.R. Swaminathan and B.G. Thomas: "Fixed Grid Techniques for Phase Change Prolems: A Review", International Journal for Numerical Methods in Engineering, 1990, vol. 30, pp. 875-98.

66. B.G. Thomas and Y. Meng: CON1D Users Manual, University of Illinois, 2002.

67. A. Kagawa and T. Okamoto: "Influence of Alloying Elements on Temperature and Composition for Peritectic Reaction in Plain Carbon Steels", Mater. Sci. Technol., 1986, vol. 2 (10), pp. 997-1008.

68. Y.M. Won and B.G. Thomas: "Simple model of microsegregation during solidification of steels", Metallurgical and Materials Transactions A (USA), 2001, vol. 32A (7), pp. 1755-67.

69. G. Li: Analysis of Thermal and Mechanical Behavior of High Heat Flux Facing Copper Walls, PhD Thesis, University of Illinois, 1996.

70. B.G. Thomas and T. Morthland: 3-D Heat Transfer Analysis of Columbus Slab Casting Mold, Columbus Steel, Report, 2001.

71. B.G. Thomas, B. Ho and G. Li: "Heat flow model of the continuous slab casting mold, interface, and shell", Alex McLean Symposium: Process Fundamentals, Liquid Metal Processing for Cleanliness, Novel and Conventional Casting, and Novel Process Technologies, (Toronto, Ontario, Canada), 1998, pp. 17793.

72. D.R. Poirier and G.H. Geiger: Transport Phenomena in Materials Processing, TMS, 1994, p. 339.

73. B.G. Thomas, D. Lui and B. Ho: "Effect of transverse depressions and oscillation marks on heat transfer in the continuous casting mold", Sensors and Modeling in Materials Processing: Techniques and Applications, (Orlando, Florida, USA), 1997, pp. 117-42.

74. M.M. Collur: Use of CON1D Model to Determine if the Casting Speed can be Increased for ChromeNickel Grades at 8-3 Caster, Allegheny Ludlum Corporation Technical Center, Report, 1996.

75. J. Paidipati, B. Sharos, C. Slayton and J. Wood: Thin-Slab Continuous Casting Mold Taper Design, University of Illinois, Report No. 6: ME280 Final Report, 2002.

76. J.K. Park: Thermo-Mechanical Phenomena in High Speed Continuous Casting Processes, PhD Thesis, University of British Columbia, 2002.

77. B.G. Thomas: "Modeling study of intermixing in tundish and strand during a continuous-casting grade transition", 79th Conference of the Steelmaking Division of the Iron and Steel Society, (Pittsburgh, PA, USA), 1996, pp. 519-31.

78. J.K. Park, B.G. Thomas and I.V. Samarasekera: "Analysis of Thermo-Mechnical Behavior in Billet Casting with Different Mold CornerRadii", ironmaking and Steelmaking, 2002, (In press).

79. R. Sobolewski, S.C. Sander, J.G. Kuczma and A.J. Rumler: "An Experimental, Instrumented Mold for Heat Transfer and Operating Conditions Study", Steelmaking Conference Proceedings, (Detroit, Michigan, USA), 1990, vol. 73, pp. 275-80.

80. I.V. Samarasekera and J.K. Brimacombe: "Thermal and Mechanical Behavior of Continous-casting Billet Molds", ironmaking and Steelmaking, 1982, vol. 9 (1), pp. 1-15.

81. D.R. Gaskell: Ann Introduction to Transport Phenomena in Materials Engineering, Macmillan Publishing Co., 1992, p. 210.

82. G.D. Lawson, S.C. Sander, W.H. Emling, A. Moritra and B.G. Thomas: "Prevention of Shell Thinning Breakouts Associated with Widening Width Changes", 77th Steelmaking Conference, (Chicago, IL, USA), 1994, vol. 77, pp. 329-36.

83. CRC Handbook of Chemistry and Physics, R.C. Weast, ed. the Chemical Rubber Co., Cleveland, Ohio, 1971.

84. R.J. Dippenaar, I.V. Samarasekera and J.K. Brimacombe: "Mold Taper in Continuous Casting Billet Machines", ISS Transactions, 1986, (7), pp. 31-43. 


\section{Appendices}

\section{A FDM Solution of Steel Solidification Model}

Figure A-1 shows the simulation domain in the solidifying steel, which is a slice through the liquid steel and solid shell and moves down at casting speed, $V_{c}$. Applying the boundary conditions:

$$
\begin{aligned}
& \left.\frac{\partial T}{\partial x}\right|_{\text {centerline }}=0 \\
& \left.k_{\text {steel }}\left(T_{s}\right) \frac{\partial T}{\partial x}\right|_{\text {steel surface }}=-q_{\text {int }}
\end{aligned}
$$

Eq.3 is solved at each time step using the following explicit central finite difference discretization:

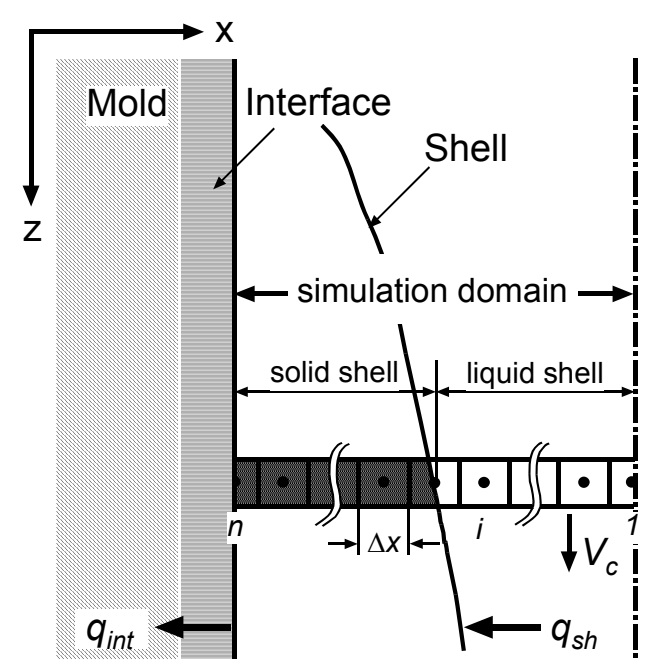

Figure A-1. Simulation domain in shell

i. Centerline liquid node (adiabatic boundary):

$$
T_{1}^{\text {new }}=T_{1}+\frac{2 \Delta t \cdot k}{\Delta x^{2} \rho C p^{*}}\left(T_{2}-T_{1}\right)
$$

ii. Interior nodes:

$$
T_{i}^{\text {new }}=T_{i}+\frac{\Delta t \cdot k}{\Delta x^{2} \rho C p^{*}}\left(T_{i-1}-2 T_{i}+T_{i+1}\right)+\frac{\Delta t}{4 \Delta x^{2} \rho C p^{*}} \frac{\partial k}{\partial T}\left(T_{i+1}-T_{i-1}\right)^{2}
$$

iii. Shell surface node (with heat flux boundary):

$$
T_{n}^{\text {new }}=T_{n}+\frac{2 \Delta t \cdot k}{\Delta x^{2} \rho C p^{*}}\left(T_{n-1}-T_{n}\right)+\frac{\Delta t}{\rho C p^{*}} \frac{\partial k}{\partial T}\left(\frac{q_{\text {int }}}{k}\right)^{2}-\frac{2 \Delta t \cdot q_{\text {int }}}{\Delta x \rho C p^{*}}
$$

The effect of superheat is included by adjusting Eq.A4 for the first interior node with a temperature below the liquidus temperature:

$$
T_{i}^{\text {new }}=T_{i}^{\text {new }}+\frac{\Delta t}{\rho C_{p}^{*} d x} q_{s h}
$$

where $d x=\Delta x$ for interior nodes, and $d x=\Delta x / 2$ for boundary nodes. 
The above equations are solved at each time step $\left(T_{i}^{\text {new }}\right)$ based on properties evaluated at the previous step $\left(T_{i}\right)$. This simple explicit scheme is usually acceptable because property changes are generally gradual with temperature. (See Figs.11, 12). However, the effective specific heat has a sudden jump when temperature drops below the liquidus temperature. To improve accuracy, and allow a larger time step, a post-iteration correction is applied to each node after the time step when it first drops below the liquidus temperature. Specifically, its temperature is increased to match the solid fraction that should have been achieved, based on converting the sensible heat extracted from that node into latent heat, according to the solid fraction curve $T\left(f_{s}\right)$ defined previously:

$$
T_{i}^{\text {new }}=T\left(f_{s}=\frac{\left(T_{\text {liq }}-T_{i}^{\text {new }}\right) \cdot C p^{*}\left(T_{i}\right)}{L_{f}}\right)
$$

\section{B Mold Thickness}

For a curved mold, the mold thickness, $d_{\text {mold }}$ varies with distance down the mold, which is calculated for the outer and inner radius mold faces separately:

$$
\begin{aligned}
& d_{\text {mold }}^{\text {outer }}=d_{\text {moldo }}^{\text {outer }}+\sqrt{R_{O}{ }^{2}-\frac{1}{4}\left(Z_{\text {mold_total }}\right)^{2}}-\sqrt{R_{O}{ }^{2}-\frac{1}{4}\left(Z_{\text {mold_total }}\right)^{2}-Z_{\text {mold_total }}^{2}} \\
& d_{\text {mold }}^{\text {inner }}=d_{\text {moldo }}^{\text {inner }}-\sqrt{R_{I}{ }^{2}-\frac{1}{4}\left(Z_{\text {mold_total }}\right)^{2}}+\sqrt{R_{I}{ }^{2}-\frac{1}{4}\left(Z_{\text {mold_total }}\right)^{2}-Z_{\text {mold_total }}^{2}}
\end{aligned}
$$

where $d_{\text {moldo }}$ is the mold thickness at the top of the mold, $Z_{\text {mold_total }}$ is the total mold length (sum of working mold length $Z_{\text {mold }}$ and distance of meniscus from top of the mold $Z_{m e n}$ ) and $R_{O}, R_{I}$ are mold outer and inner radius of curvature respectively.

\section{Equilibrium Partition Coefficient, Diffusion Coefficient, and Liquidus Line Slopes of the}

\section{Solute Element}

The microsegregation model used here ${ }^{[68]}$ evaluates dendrite arm spacing and phase fraction evolution as a function of cooling rate, $C_{R}$ and steel composition, $C_{0}$. Liquidus, solidus and peritectic temperatures depend on steel composition as follows:

$$
T_{\text {liq }}=T_{\text {pure }}-\sum_{i} m_{i} \cdot C_{0, i}
$$




$$
\begin{aligned}
& T_{\text {sol }}=T_{\text {pure }}-\sum_{i} m_{i} \cdot C_{L, i}\left(C_{0, i}, k_{i}, D_{i}, C_{R}, f_{s}=1\right) \\
& T^{\delta / \gamma}=T_{\text {pure }}^{\delta / \gamma}-\sum_{i} n_{i} \cdot k_{i}^{\delta / \gamma} \cdot C_{L, i}^{\delta}
\end{aligned}
$$

Extended data needed for this model are listed in the following table and include the partition coefficients, $k$ and diffusion coefficients, $D$ for each phase, and the slopes of the equilibrium liquidus m, and the slopes of $A r_{4}$ lines, $\mathrm{n}$ for the pseudo-binary alloy of each element with iron. The results are not very sensitive to cooling rate, as the accompanying dendrite arm spacing change tends to compensate.

\begin{tabular}{lllllll}
\hline Element & $k^{\delta L}$ & $k^{\gamma / L}$ & $D^{\delta}\left(\mathrm{cm}^{2} / \mathrm{sec}\right)$ & $D^{\gamma}\left(\mathrm{cm}^{2} / \mathrm{sec}\right)$ & $m\left({ }^{\circ} \mathrm{C} / \%\right)$ & $n\left({ }^{\circ} \mathrm{C} / \%\right)$ \\
\hline $\mathrm{C}$ & 0.19 & 0.34 & $0.0127 \exp (-19450 / \mathrm{RT})$ & $0.0761 \exp (-32160 / \mathrm{RT})$ & 78.0 & -1122 \\
$\mathrm{Si}$ & 0.77 & 0.52 & $8.0 \exp (-59500 / \mathrm{RT})$ & $0.3 \exp (-60100 / \mathrm{RT})$ & 7.6 & 60 \\
$\mathrm{Mn}$ & 0.76 & 0.78 & $0.76 \exp (-53640 / \mathrm{RT})$ & $0.055 \exp (-59600 / \mathrm{RT})$ & 4.9 & -12 \\
$\mathrm{P}$ & 0.23 & 0.13 & $2.9 \exp (-55000 / \mathrm{RT})$ & $0.01 \exp (-43700 / \mathrm{RT})$ & 34.4 & 140 \\
$\mathrm{~S}$ & 0.05 & 0.035 & $4.56 \exp (-51300 / \mathrm{RT})$ & $2.4 \exp (-53400 / \mathrm{RT})$ & 38.0 & 160 \\
$\mathrm{Cr}$ & 0.95 & 0.86 & $2.4 \exp (-57310 / \mathrm{RT})$ & $0.0012 \exp (-52340 / \mathrm{RT})$ & 1.04 & 13.4 \\
$\mathrm{Ni}$ & 0.83 & 0.95 & $1.6 \exp (-57360 / \mathrm{RT})$ & $0.34 \exp (-67490 / \mathrm{RT})$ & 4.69 & -28.6 \\
$\mathrm{Cu}$ & 0.53 & 0.88 & $2.6 \exp (-57360 / \mathrm{RT})$ & $0.7 \exp (-68350 / \mathrm{RT})$ & 5.32 & -10.4 \\
$\mathrm{Mo}$ & 0.80 & 0.585 & $3.47 \exp (-57690 / \mathrm{RT})$ & $0.068 \exp (-59000 / \mathrm{RT})$ & 2.6 & 77.6 \\
$\mathrm{Ti}$ & 0.38 & 0.33 & $3.15 \exp (-59200 / \mathrm{RT})$ & $0.15 \exp (-59980 / \mathrm{RT})$ & 10.24 & 120.5 \\
$\mathrm{~V}$ & 0.93 & 0.63 & $4.8 \exp (-57360 / \mathrm{RT})$ & $0.284 \exp (-61900 / \mathrm{RT})$ & 12.95 & 85.5 \\
$\mathrm{Nb}$ & 0.40 & 0.22 & $50.2 \exp (-60220 / \mathrm{RT})$ & $0.83 \exp (-63690 / \mathrm{RT})$ & 10.24 & 70.8 \\
$\mathrm{~W}$ & 0.85 & 0.45 & $1.57 \exp (-58200 / \mathrm{RT})$ & $0.13 \exp (-57300 / \mathrm{RT})$ & 0.24 & 18.8 \\
$\mathrm{~N}$ & 0.25 & 0.48 & $0.008 \exp (-18900 / \mathrm{RT})$ & $0.91 \exp (-40270 / \mathrm{RT})$ & 60.0 & -
\end{tabular}

Note: $\mathrm{R}$ is gas constant of $1.987 \mathrm{cal} / \mathrm{mol} \mathrm{K}$, and $\mathrm{T}$ is temperature in Kelvin.

\section{Carbon Steel Thermal Properties Functions}

1. Thermal conductivities 
$k=k_{\alpha} f_{\alpha}+k_{\delta} f_{\delta}+k_{\gamma} f_{\gamma}+k_{l} f_{l}$

where

$k_{\alpha}=\left(80.91-9.9269 \times 10^{-2} T+4.613 \times 10^{-5} T^{2}\right)\left(1-a_{1}(C \%)^{a_{2}}\right)$

$k_{\delta}=\left(20.14-9.313 \times 10^{-3} T\right)\left(1-a_{1}(C \%)^{a_{2}}\right)$

$k_{\gamma}=21.6-8.35 \times 10^{-3} \mathrm{~T}$

$k_{l}=39.0$

$a_{1}=0.425-4.385 \times 10^{-4} \mathrm{~T} \quad a_{2}=0.209+1.09 \times 10^{-3} \mathrm{~T}$

2. Specific heat

$C_{p}=C_{p}^{\alpha} f_{\alpha}+C_{p}^{\delta} f_{\delta}+C_{p}^{\gamma} f_{\gamma}+C_{p}^{l} f_{l}$

where

$C_{p}^{\alpha}= \begin{cases}504.8146-0.1311139 T(K)-5.1875834 \times 10^{6} T(K)^{-2} & T(K) \leq 800 \\ +4.486659 \times 10^{-4} T(K)^{2} & \\ -4720.324+4.583364 T(K)+1.109483 \times 10^{9} T(K)^{-2} & 800<T(K) \leq 1000 \\ -11501.07+12.476362 T(K) & 1000<T(K) \leq 1042 \\ 34871.21-32.02658 T(K) & 1042<T(K) \leq 1060 \\ -10068.18+5.98686 T(K)+5.217657 \times 10^{9} T(K)^{-2} & 1060<T(K) \leq 1184\end{cases}$
$C_{p}^{\delta}=441.3942+0.17744236 T(K)$
$C_{p}^{\gamma}=429.8495+0.1497802 T(K)$
$C_{p}^{l}=824.6157$

3. Density used for Thermal Linear Expansion Calculation

$\rho(T)=\rho_{\alpha} f_{\alpha}+\rho_{\delta} f_{\delta}+\rho_{\gamma} f_{\gamma}+\rho_{l} f_{l}$

where

$\rho_{\alpha}=7880.76-0.3244 T-2.7461 \times 10^{-5} T^{2}$

$\rho_{\delta}=(8010.71-0.4724 T) \cdot\left(1+\frac{C \%}{100-C \%}\right) \cdot\left(1+13.43 \times 10^{-3} \% C\right)^{-3}$

[D3]

$\rho_{\gamma}=(8105.91-0.5091 T) \cdot\left(1+\frac{C \%}{100-C \%}\right) \cdot\left(1+8.317 \times 10^{-3} \% C\right)^{-3}$

$\rho_{l}=7965.98-0.619 T$ 
List of Tables and Figures

Table I. Constants Used in Analytical Solution and Validation Case

Table II. Standard Input Conditions (Case 1)

Table III. Input Conditions for Sub-Mold Calibration (China Steel Case)

Table IV. Spray Zone Variables (China Steel Case)

Table V. Parametric Study Conditions

Figure 1. Schematic of continuous casting process showing slag layers (not to scale)

Figure 2. Model of solidifying steel shell domain showing typical isotherms and heat flux conditions

Figure 3. Thermal resistances used in the interface model

Figure 4. Model treatment of oscillation marks

Figure 5. Comparison of model mold slag viscosity curves and measurements ${ }^{[53]}$

Figure 6. Velocity and temperature profiles assumed across interfacial gap

Figure 7. Simulation domain in mold a) Vertical section along casting direction

b) Horizontal section through mold

Figure 8. Schematic of spray zone region

Figure 9. Flow chart of CON1D program with 1D steel solidification model and 2D mold heat conduction model

Figure 10. Phase fraction variation with temperature in mushy zone

Figure 11. Comparison of model thermal conductivities and measurements ${ }^{[45]}$

Figure 12. Comparison of model specific heat curve and measurements ${ }^{[45]}$

Figure 13. Comparison of model results and analytical solution

Figure 14. Comparison of CON1D predicted and measured mold temperature

Figure 15. Comparison of CON1D predicted and measured shell thickness

Figure 16. Predicted slag layer thickness profiles

Figure 17. Predicted shell surface temperature

Figure 18. Shell temperature (China Steel Case)

Figure 19. Effect of casting speed and powder consumption on the heat flux profile

Figure 20. Effect of casting speed on mold temperature

Figure 21. Effect of casting speed on shell thickness

Figure 22. Effect of casting speed on steel shell temperature

Figure 23. Effect of casting speed on slag layer thickness

Figure 24. Effect of casting speed on shell temperature profile at mold exit

Figure 25. Effect of casting speed on shell shrinkage 
Table I. Constants Used in Analytical Solution and Validation Case

\begin{tabular}{l|ll}
\hline Conductivity, $k_{\text {steel }}$ & 30.0 & $\mathrm{~W} / \mathrm{mK}$ \\
Specific Heat, $C p_{\text {steel }}$ & 670.0 & $\mathrm{~J} / \mathrm{kgK}$ \\
Latent Heat, $L_{f}$ & 271.0 & $\mathrm{~kJ} / \mathrm{kg}$ \\
Density, $\rho_{\text {steel }}$ & 7400.0 & $\mathrm{~kg} / \mathrm{m}^{3}$ \\
Melting Temperature, $T_{\text {melt }}$ & 1509.05 & ${ }^{\circ} \mathrm{C}$ \\
Liquidus Temperature, $T_{\text {liq }}$ & 1509.1 & ${ }^{\circ} \mathrm{C}$ \\
Solidus Temperature, $T_{\text {sol }}$ & 1509 & ${ }^{\circ} \mathrm{C}$ \\
Shell Surface Temperature, $T_{s}$ & 1000 & ${ }^{\circ} \mathrm{C}$ \\
\hline
\end{tabular}


Table II. Standard Input Conditions (Case 1)

\begin{tabular}{|c|c|c|}
\hline Carbon Content, $\mathrm{C} \%$ & 0.044 & $\%$ \\
\hline Liquidus Temperature, $T_{l i q}$ & 1529 & ${ }^{\circ} \mathrm{C}$ \\
\hline Solidus Temperature, $T_{\text {sol }}$ & 1509 & ${ }^{\circ} \mathrm{C}$ \\
\hline Steel Density, $\rho_{\text {steel }}$ & 7400 & $\mathrm{~kg} / \mathrm{m}^{2}$ \\
\hline Steel Emissivity, $\varepsilon_{\text {steel }}$ & 0.8 & - \\
\hline Fraction Solid for Shell Thickness Location, $f_{s}$ & 0.1 & - \\
\hline Mold Thickness at Top (Outer face, including water channel) & 56.8 & $\mathrm{~mm}$ \\
\hline Mold Outer Face Radius, $R_{o}$ & 11.985 & $\mathrm{~m}$ \\
\hline Total Mold Length, $Z_{\text {mold_total }}$ & 900 & $\mathrm{~mm}$ \\
\hline Total Mold Width & 1876 & $\mathrm{~mm}$ \\
\hline Scale thickness at mold cold face (inserts region/ below), $d_{\text {scale }}$ & $0.02 / 0.01$ & $\mathrm{~mm}$ \\
\hline Initial Cooling Water Temperature, $T_{\text {water }}$ & 30 & ${ }^{\circ} \mathrm{C}$ \\
\hline Water Channel Geometry, $d_{c h} \times w_{c h} \times L_{c h}$ & $25 \times 5 \times 29$ & $\mathrm{~mm}^{3}$ \\
\hline Cooling Water Velocity, $V_{\text {water }}$ & 7.8 & $\mathrm{~m} / \mathrm{s}$ \\
\hline Mold Conductivity, $k_{\text {mold }}$ & 315 & $\mathrm{~W} / \mathrm{mK}$ \\
\hline Mold Emissivity, $\varepsilon_{\text {mold }}$ & 0.5 & - \\
\hline Mold Powder Solidification Temperature, $T_{f s o l}$ & 1045 & ${ }^{\circ} \mathrm{C}$ \\
\hline Mold Powder Conductivity, $k_{\text {solid }} / k_{\text {liquid }}$ & $1.5 / 1.5$ & $\mathrm{~W} / \mathrm{mK}$ \\
\hline Air Conductivity, $k_{\text {air }}$ & 0.06 & $\mathrm{~W} / \mathrm{mK}$ \\
\hline Slag Layer/Mold Resistance, $r_{\text {contact }}$ & $5.0 \mathrm{E}-9$ & $\mathrm{~m}^{2} \mathrm{~K} / \mathrm{W}$ \\
\hline Mold Powder Viscosity at $1300^{\circ} \mathrm{C}, \mu_{1300}$ & 1.1 & Poise \\
\hline Exponent for Temperature dependence of Viscosity, $n$ & 0.85 & - \\
\hline Slag Density, $\rho_{\text {slag }}$ & 2500 & $\mathrm{~kg} / \mathrm{m}^{3}$ \\
\hline Slag Absorption Factor, $a$ & 250 & $\mathrm{~m}^{-1}$ \\
\hline Slag Refractive Index, $m$ & 1.5 & - \\
\hline Slag Emissivity, $\varepsilon_{\text {slag }}$ & 0.9 & - \\
\hline Mold Powder Consumption Rate, $Q_{\text {slag }}$ & 0.6 & $\mathrm{~kg} / \mathrm{m}^{2}$ \\
\hline Empirical solid slag layer speed factor, $f_{v}$ & 0.175 & - \\
\hline Casting Speed, $V_{c}$ & 1.07 & $\mathrm{~m} / \mathrm{min}$ \\
\hline Pour Temperature, $T_{\text {pour }}$ & 1550 & ${ }^{\circ} \mathrm{C}$ \\
\hline Slab Geometry, $W \times N$ & $1780 \times 225$ & $\mathrm{~mm} \times \mathrm{mm}$ \\
\hline Nozzle Submergence Depth, $d_{\text {nozzle }}$ & 265 & $\mathrm{~mm}$ \\
\hline Working Mold Length, $Z_{\text {mold }}$ & 810 & $\mathrm{~mm}$ \\
\hline Oscillation Mark Geometry, $d_{\text {mark }} \times w_{\text {mark }}$ & $0.45 \times 4.5$ & $\mathrm{~mm} \times \mathrm{mm}$ \\
\hline Mold Oscillation Frequency, freq & 84 & cpm \\
\hline Oscillation Stroke, stroke & 10 & $\mathrm{~mm}$ \\
\hline Time Step, $d t$ & 0.004 & $\mathrm{~s}$ \\
\hline Mesh Size, $d x$ & 0.5 & $\mathrm{~mm}$ \\
\hline
\end{tabular}


Table III. Input Conditions for Sub-Mold Calibration (China Steel Case)

\begin{tabular}{l|ll}
\hline Carbon Content, $C \%$ & 0.45 & $\%$ \\
Mold Thickness at Top (including water channel) & 51 & $\mathrm{~mm}$ \\
Initial Cooling Water Temperature, $T_{\text {water }}$ & 35 & ${ }^{\circ} \mathrm{C}$ \\
Water Channel Geometry, $d_{c h} \times w_{c h} \times L_{c h}$ & $25 \times 5 \times 28$ & $\mathrm{~mm}^{3}$ \\
Cooling Water velocity, $V_{\text {water }}$ & 7.62 & $\mathrm{~m} / \mathrm{s}$ \\
Casting Speed, $V_{c}$ & 0.55 & $\mathrm{~m} / \mathrm{min}$ \\
Pour Temperature, $T_{\text {pour }}$ & 1510 & ${ }^{\circ} \mathrm{C}$ \\
Slab Geometry, $W \times N$ & $1560 \times 270$ & $\mathrm{~mm} \times \mathrm{mm}$ \\
Nozzle Submergence Depth, $d_{\text {nozzle }}$ & 200 & $\mathrm{~mm}$ \\
Working Mold Length, $Z_{\text {mold }}$ & 600 & $\mathrm{~mm}$ \\
Mold Oscillation Frequency, freq & 120 & $\mathrm{cpm}$ \\
Oscillation Stroke, stroke & 4 & $\mathrm{~mm}$ \\
Cooling Water Temperature in Spray Zones, $T_{\text {spray }}$ & 35 & ${ }^{\circ} \mathrm{C}$ \\
Spray Length of Spray Zone Nozzle, $L_{\text {spray }}$ & 0.05 & $\mathrm{~m}$ \\
Spray Zone Roll Contact Angle & 7 & Degree \\
\hline
\end{tabular}

Table IV. Spray Zone Variables (China Steel Case)

\begin{tabular}{ccccccc}
\hline Zone \# & $\begin{array}{c}\text { Zone Starts at } \\
(\mathrm{mm})\end{array}$ & Roll \# in Zone & $\begin{array}{c}\text { Roll Radius } \\
(\mathrm{mm})\end{array}$ & $\begin{array}{c}\text { Water Flow Rate } \\
(1 / \mathrm{min} / \text { row })\end{array}$ & $\begin{array}{c}\text { Spray Width } \\
(\mathrm{m})\end{array}$ & $f_{\text {roll }}$ \\
\hline 1 & 600.0 & 2 & 70 & 27.5 & 1.3 & 0.05 \\
2 & 906.9 & 5 & 70 & 14.86 & 1.2 & 0.05 \\
3 & 1840.8 & 5 & 100 & 14.86 & 1.2 & 0.05 \\
4 & 3034.3 & 5 & 125 & 11.84 & 1.2 & 0.2 \\
5 & 4520.5 & 10 & 150 & 8.8 & 1.2 & 0.2 \\
6 & 7977.9 & 10 & 175 & 7.15 & 1.2 & 0.2 \\
7 & 11883.1 & 11 & 210 & 2.5 & 1.56 & 0.2 \\
8 & 17050.7 & 18 & 240 & 0.0 & 1.56 & 0.2 \\
& 26440.7 & End of last spray zone \\
\hline \multicolumn{7}{r}{}
\end{tabular}

Table V. Parametric Study Conditions

\begin{tabular}{ccccc}
\hline & $\begin{array}{c}\text { Casting Speed } \\
V_{c}(\mathrm{~m} / \mathrm{min})\end{array}$ & $\begin{array}{c}\text { Oscillation } \\
\text { frequency } \\
\text { freq }(\mathrm{cpm})\end{array}$ & $\begin{array}{c}\text { Total Consumption Rate } \\
Q_{\text {slag }}\left(\mathrm{kg} / \mathrm{m}^{2}\right)\end{array}$ & $\begin{array}{c}\text { Osc. Mark Size } \\
d_{\text {mark }} \times w_{\text {mark }}\left(\mathrm{mm}^{2}\right)\end{array}$ \\
\hline Case 1 & 1.07 & 84 & .60 & $.45 \times 4.5$ \\
Case 2 & 1.07 & 84 & .56 & $.45 \times 4.5$ \\
Case 3 & 1.25 & 98 & .56 & $.40 \times 4.0$ \\
\hline
\end{tabular}




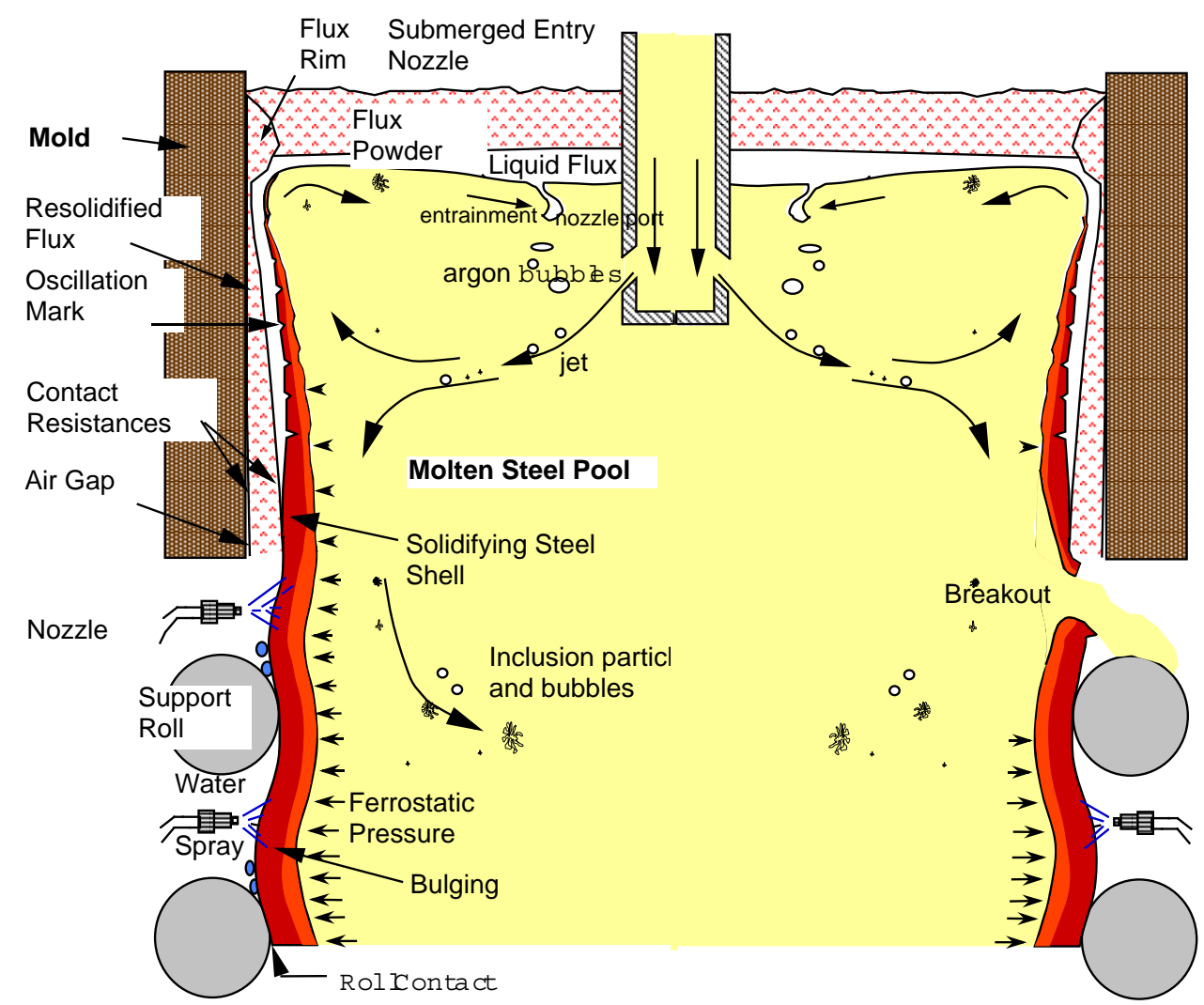

Figure 1. Schematic of continuous casting process showing slag layers (not to scale)

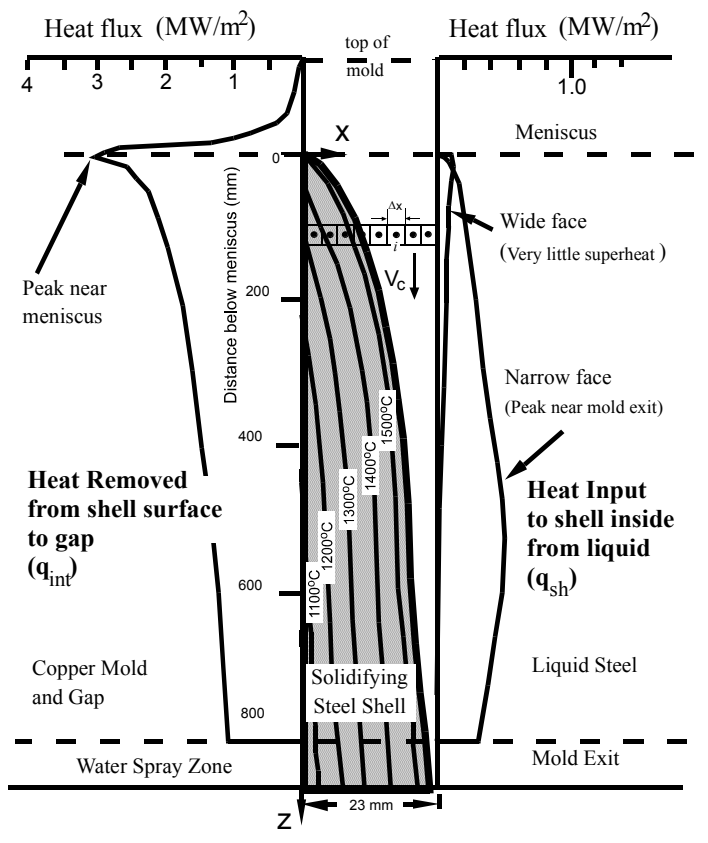

Figure 2. Model of solidifying steel shell domain showing typical isotherms and heat flux conditions 


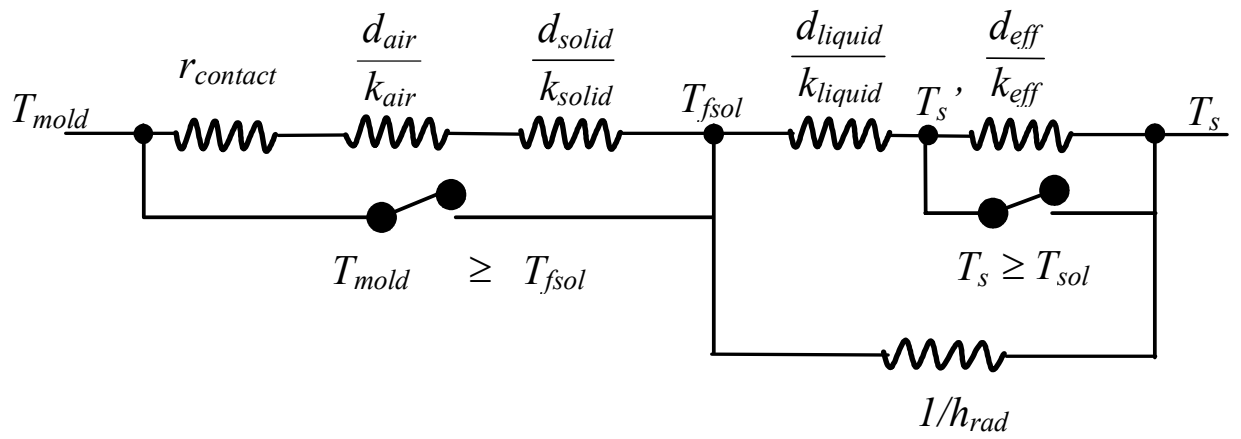

Figure 3. Thermal resistances used in the interface model

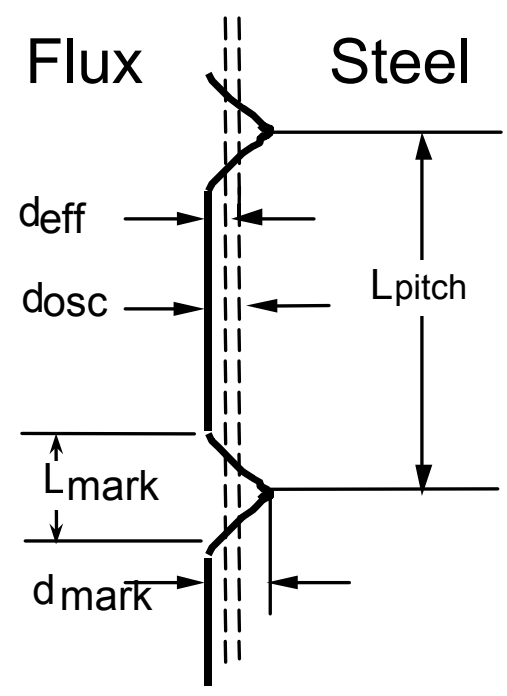

Figure 4. Model treatment of oscillation marks

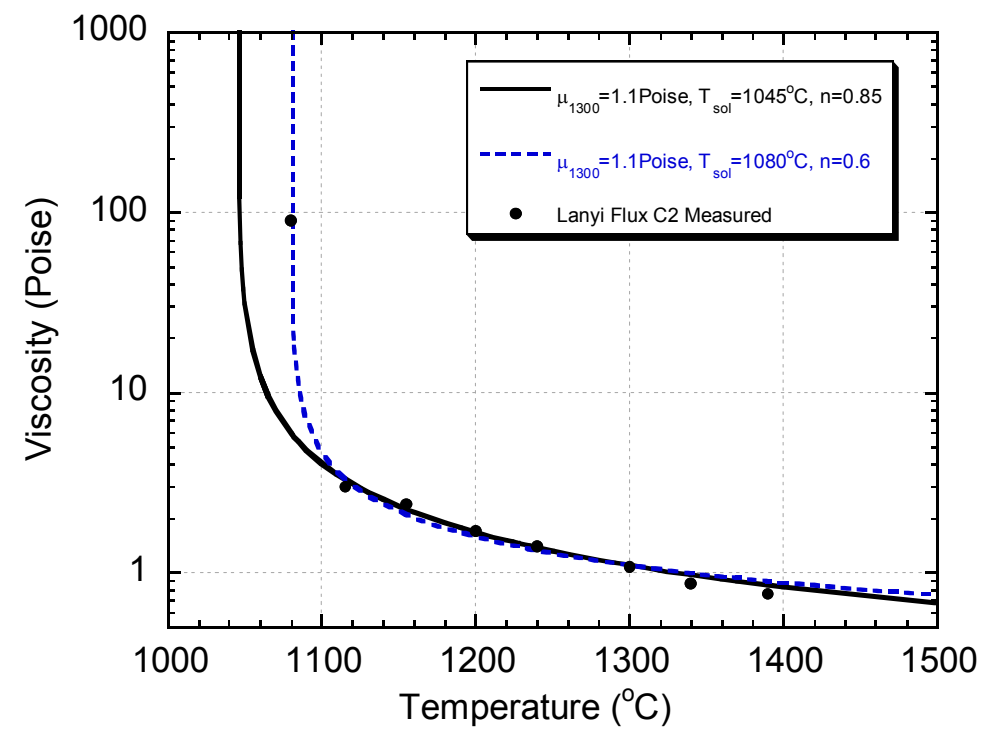

Figure 5. Comparison of model mold slag viscosity curves and measurements ${ }^{[53]}$ 


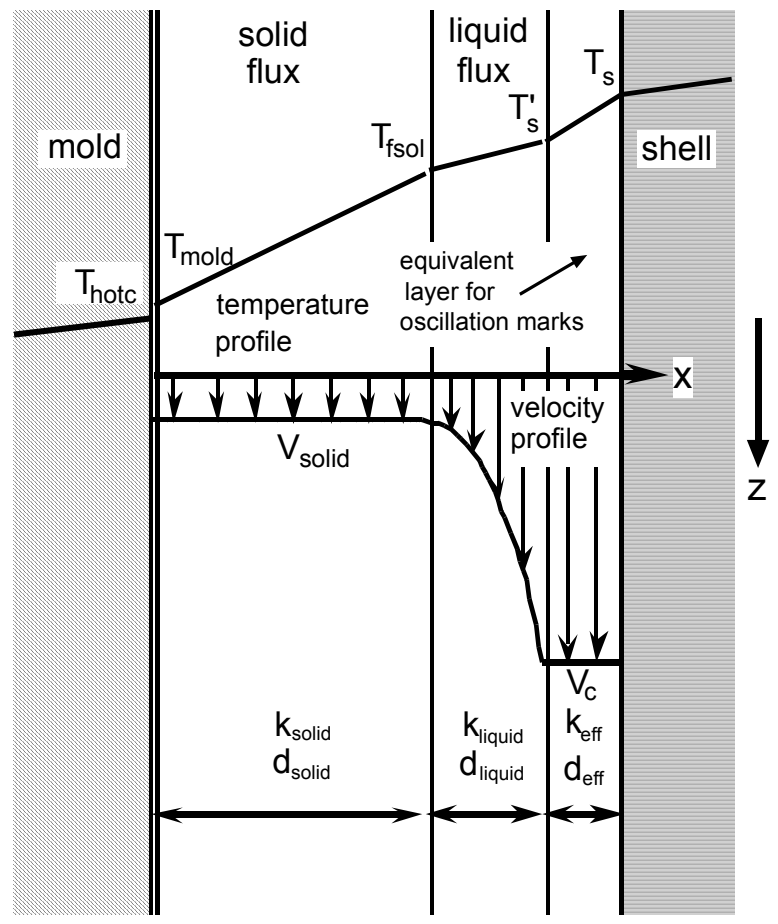

Figure 6. Velocity and temperature profiles assumed across interfacial gap

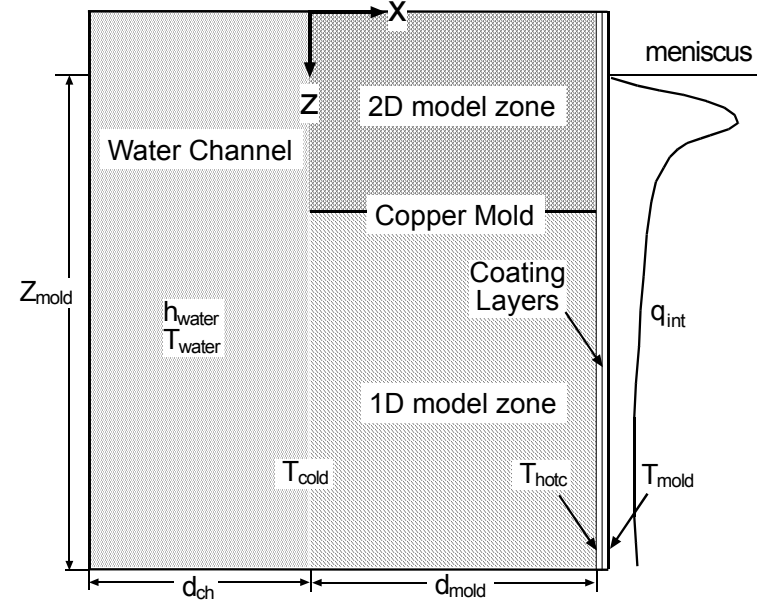

(a) Vertical section along casting direction

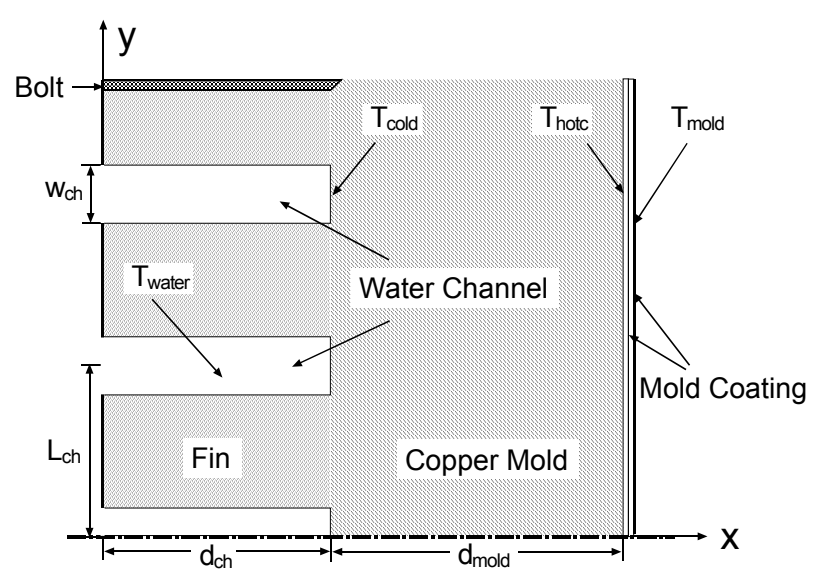

(b) Horizontal section through mold

Figure 7. Simulation domain in mold 

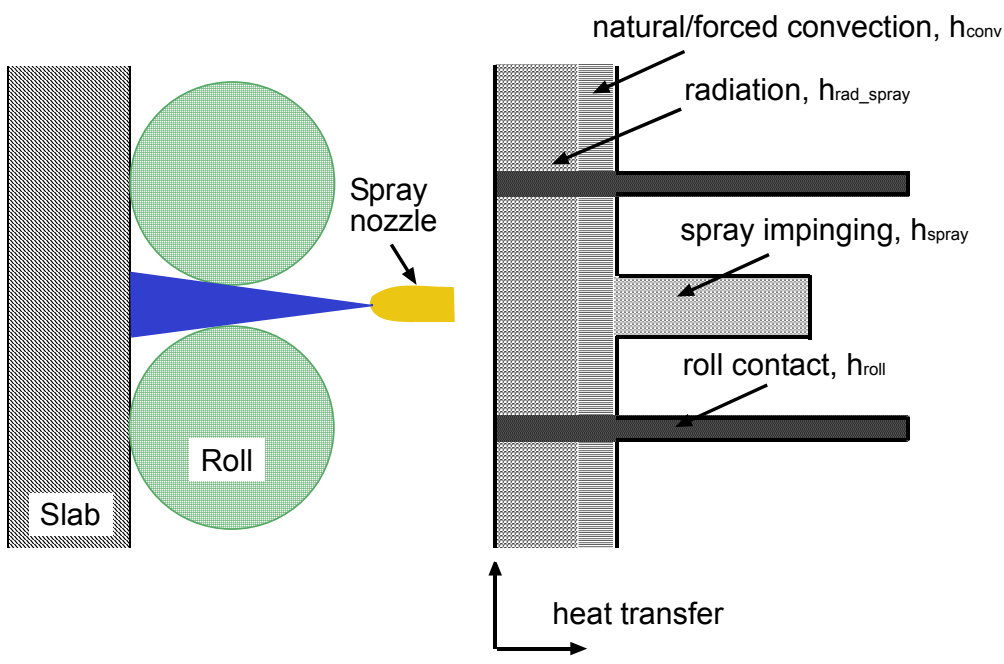

Figure 8. Schematic of spray zone region

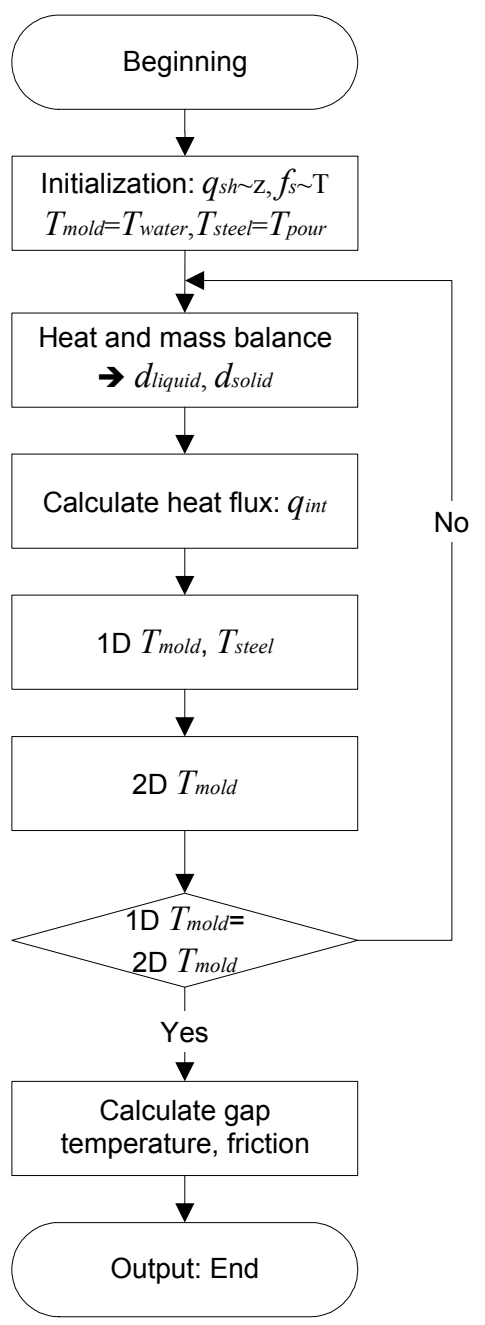

Figure 9. Flow chart of CON1D program with 1D steel solidification model and $2 \mathrm{D}$ mold heat conduction model 


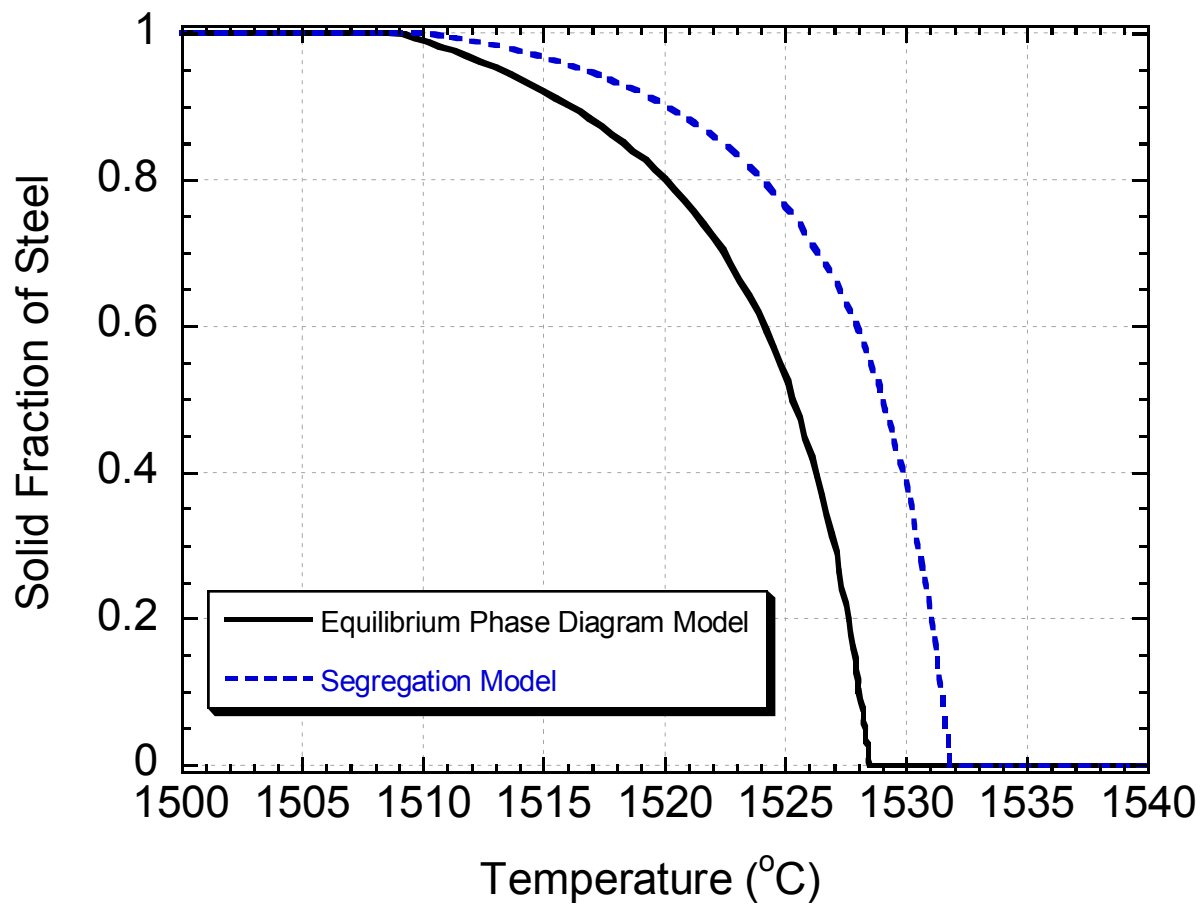

Figure 10. Phase fraction variation with temperature in mushy zone

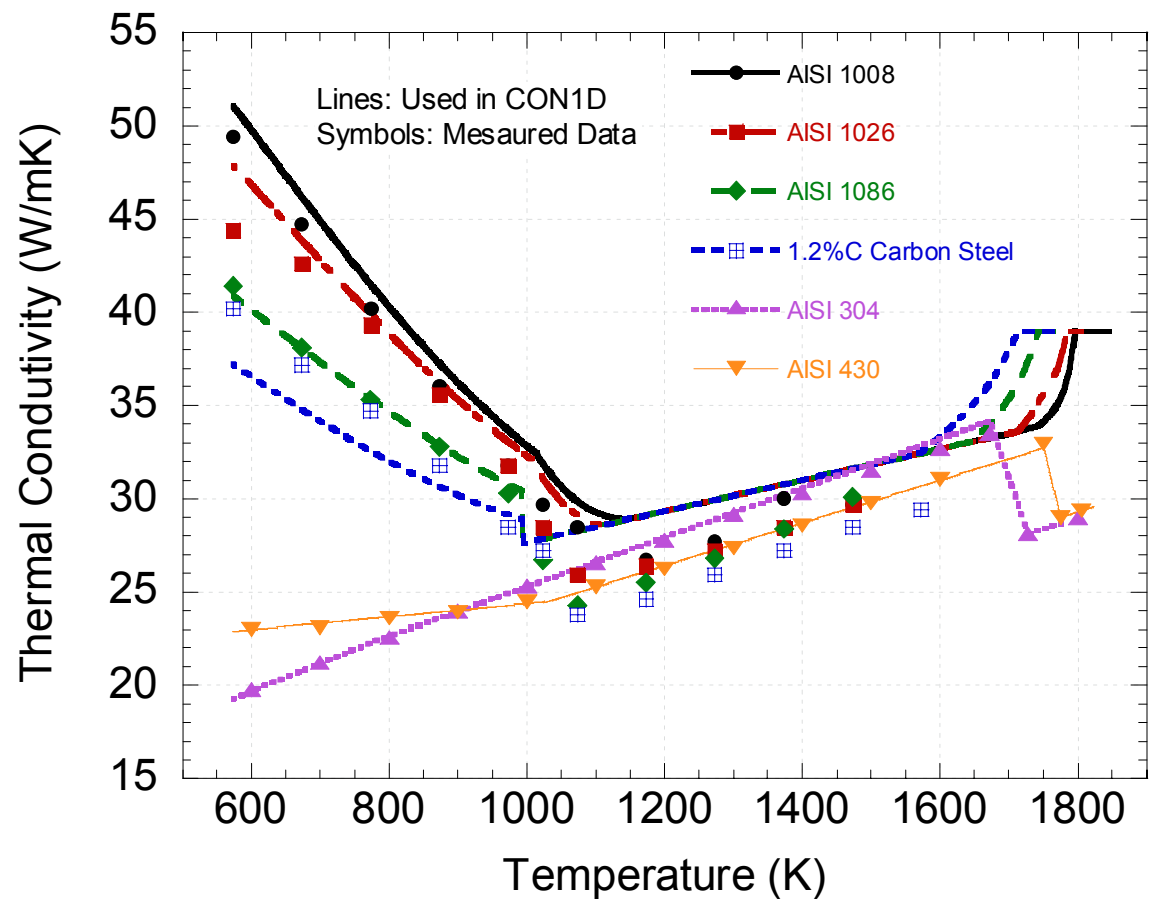

Figure 11. Comparison of model thermal conductivities and measurements ${ }^{[45]}$ 


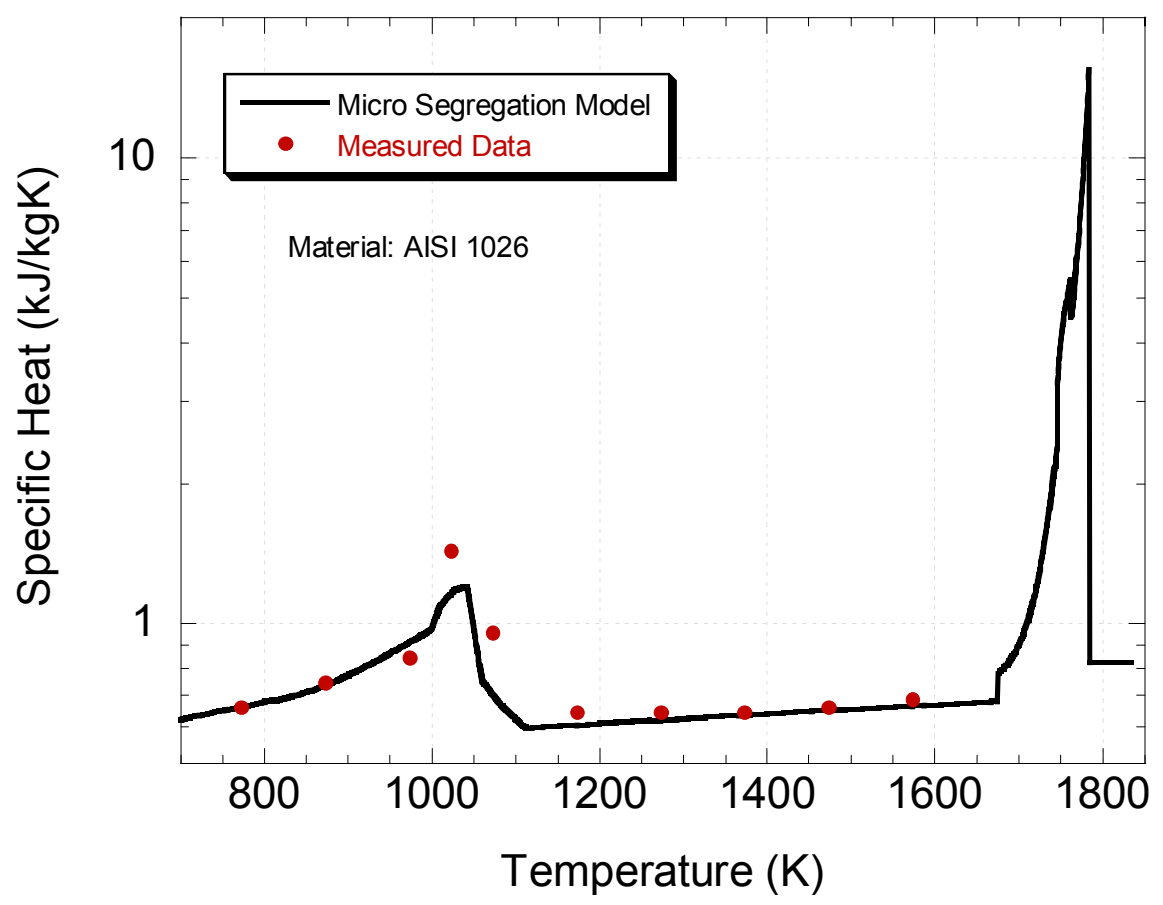

Figure 12. Comparison of model specific heat curve and measurements ${ }^{[45]}$

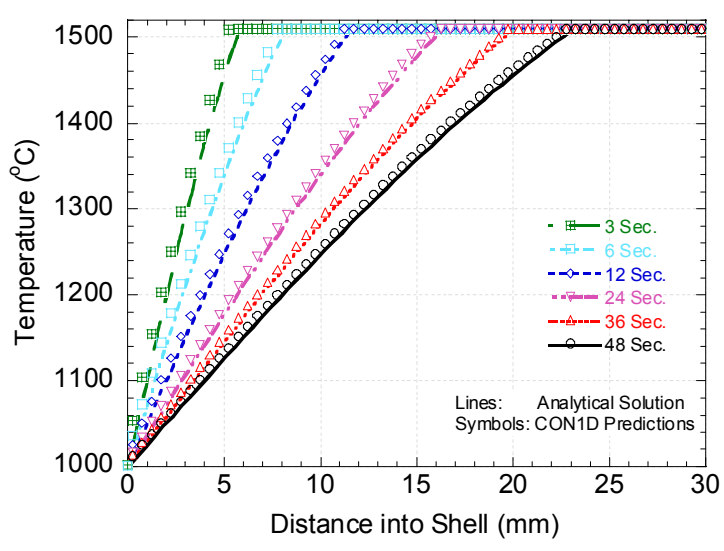

(a) Shell temperature distribution

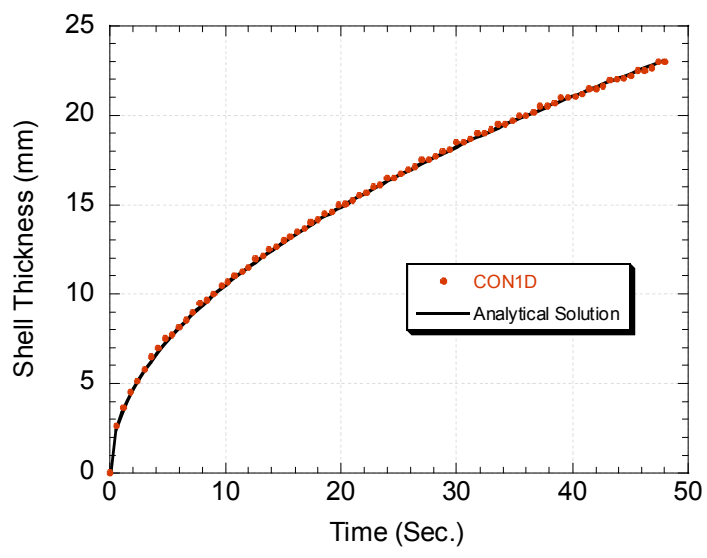

(b) Shell growth

Figure 13. Comparison of CON1D model results and analytical solutions 


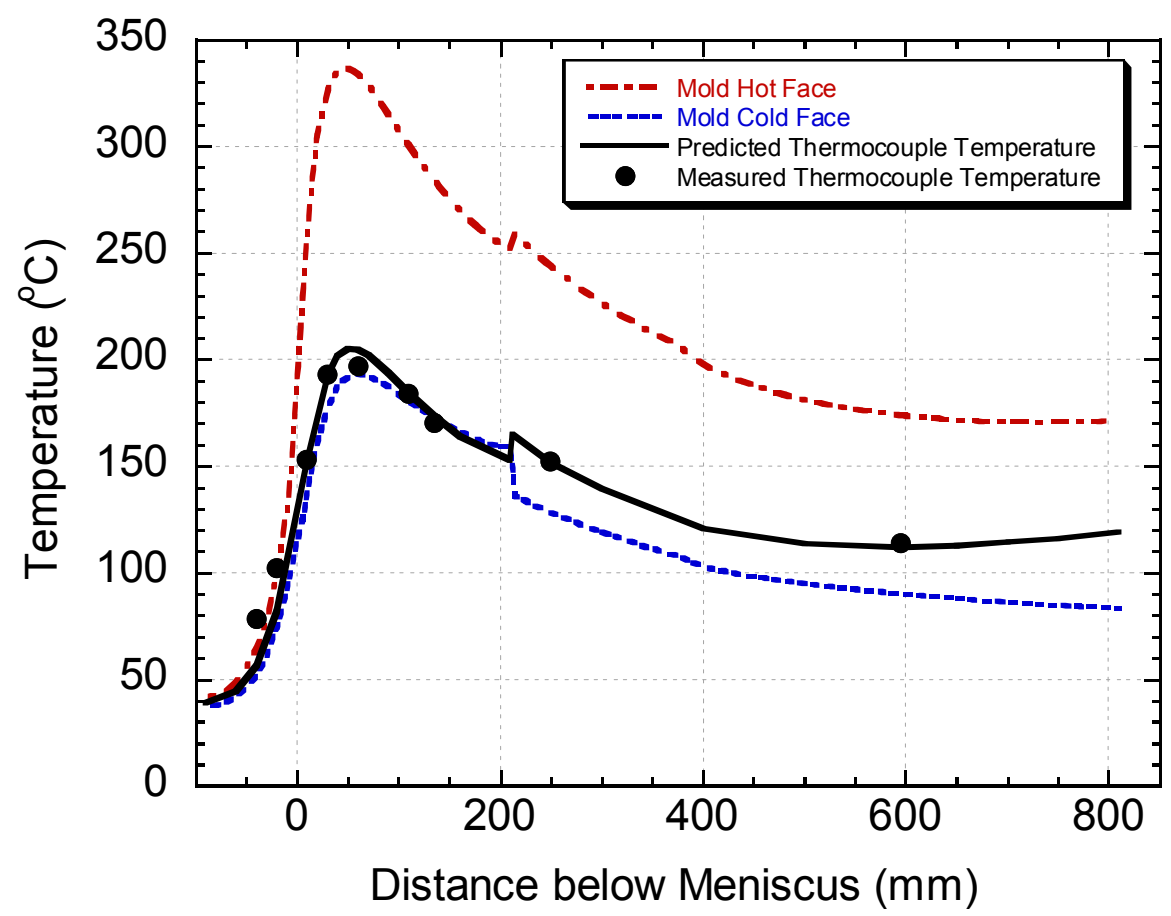

Figure 14. Comparison of CON1D predicted and measured mold temperature

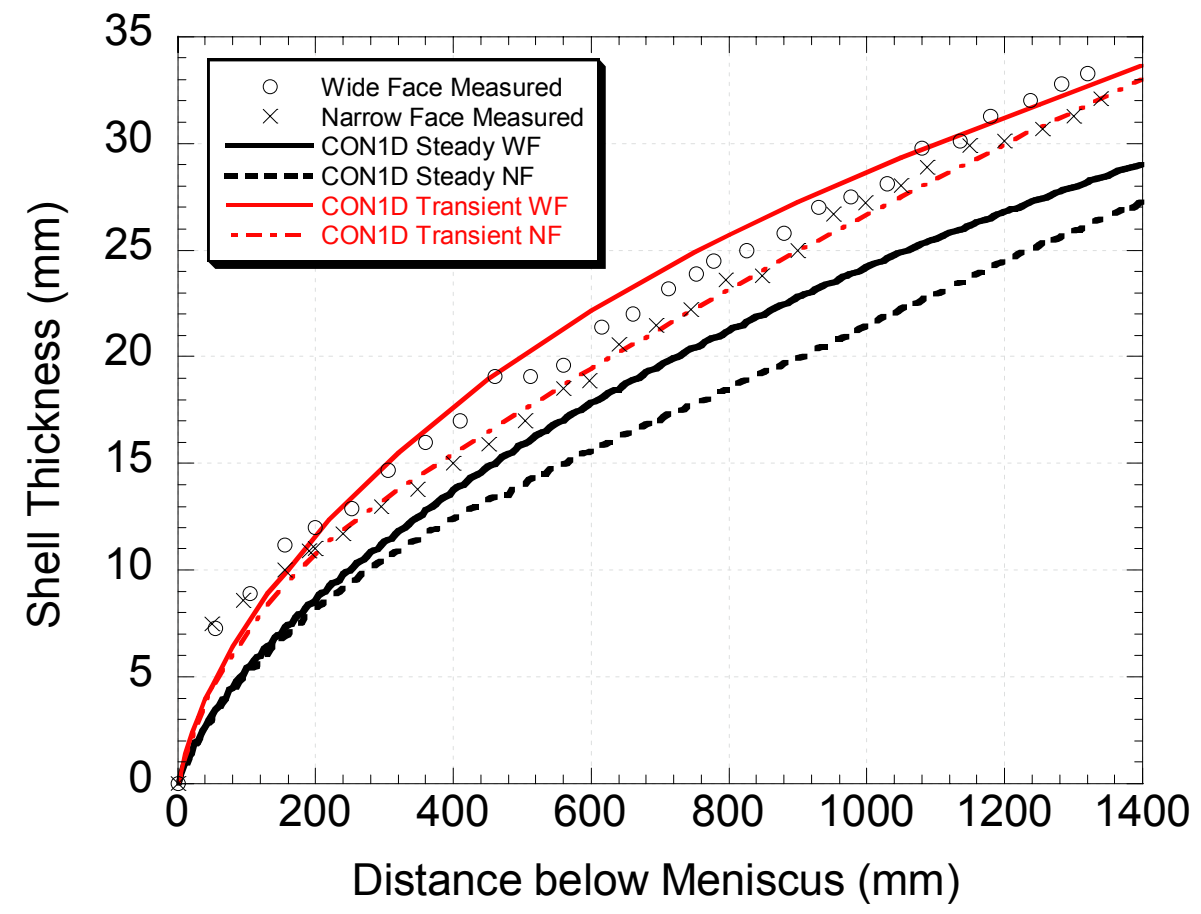

Figure 15. Comparison of CON1D predicted and measured shell thickness 


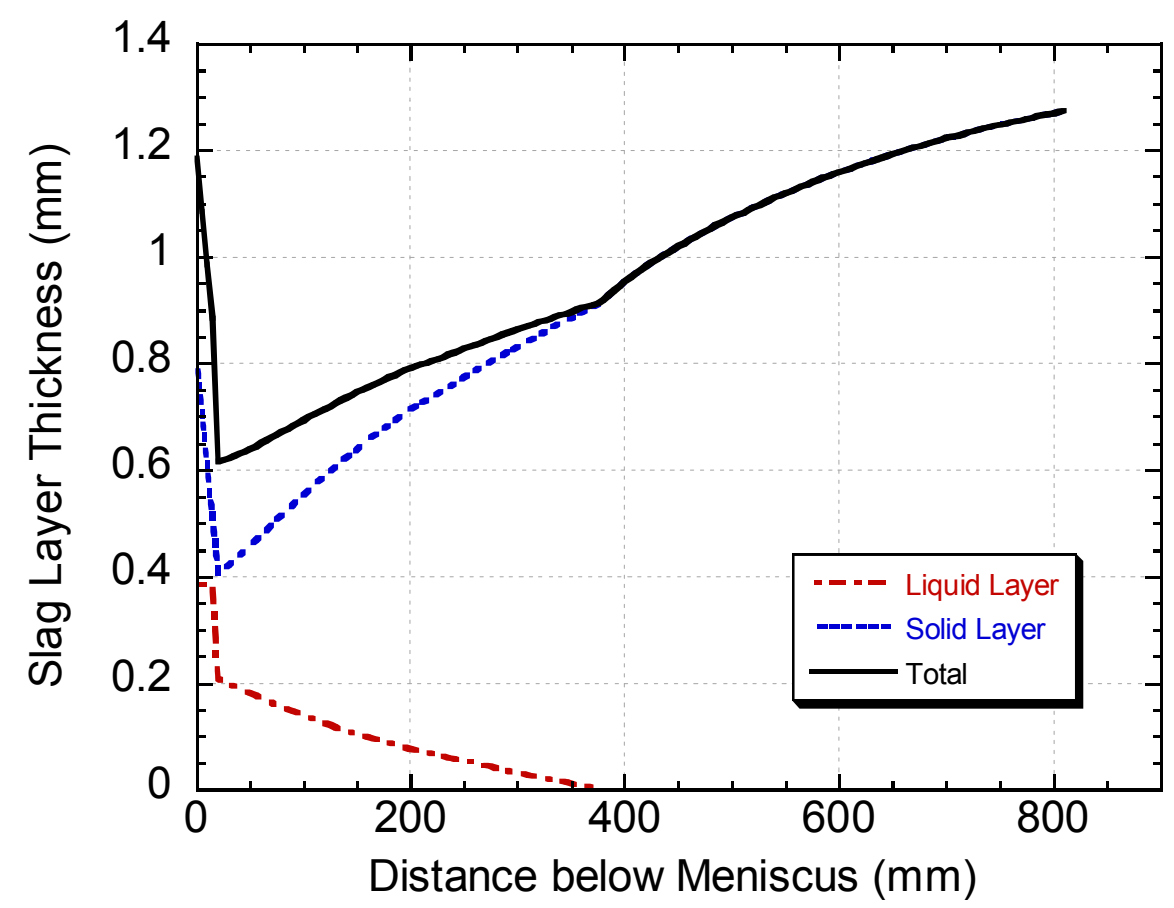

Figure 16. Predicted slag layer thickness profiles

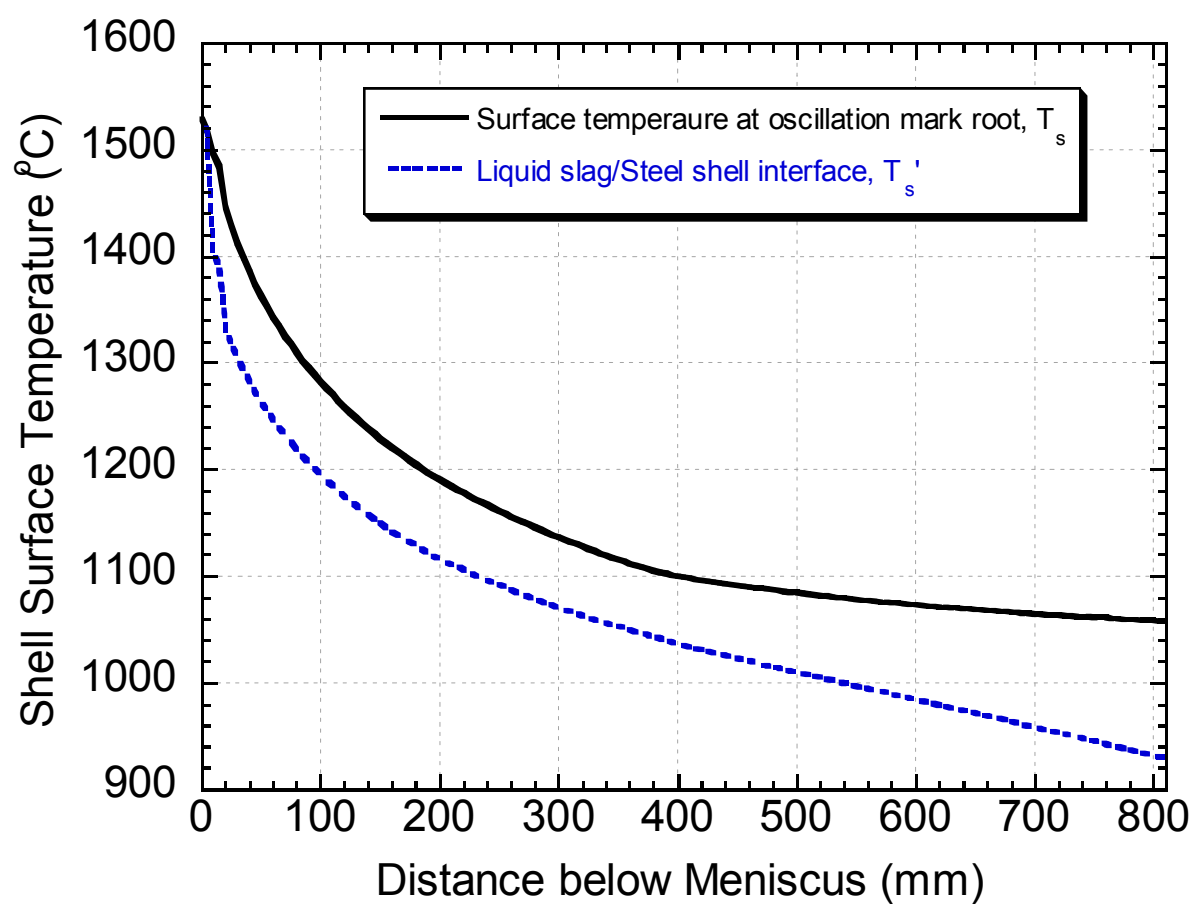

Figure 17. Predicted shell surface temperature 


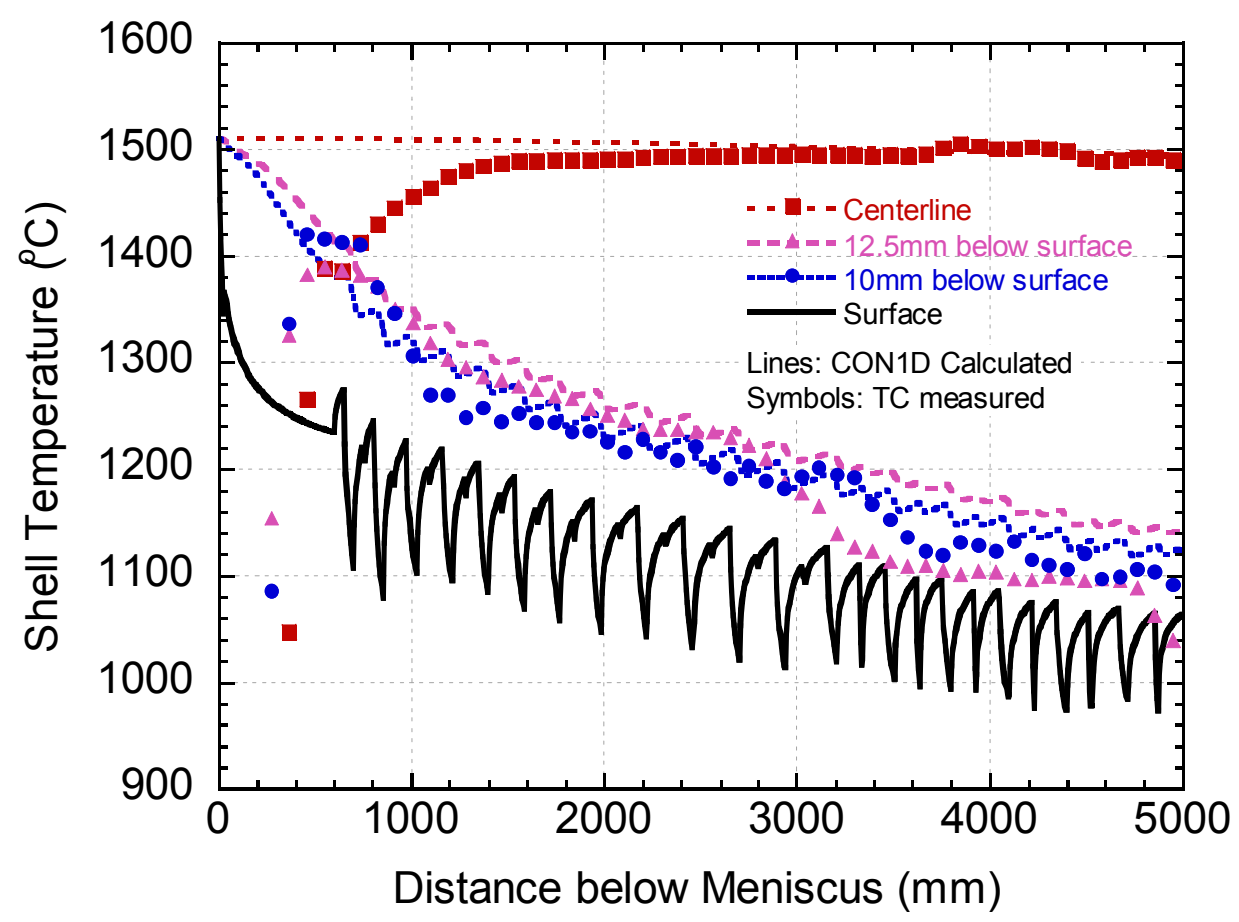

Figure 18. Shell temperature (China Steel Case)

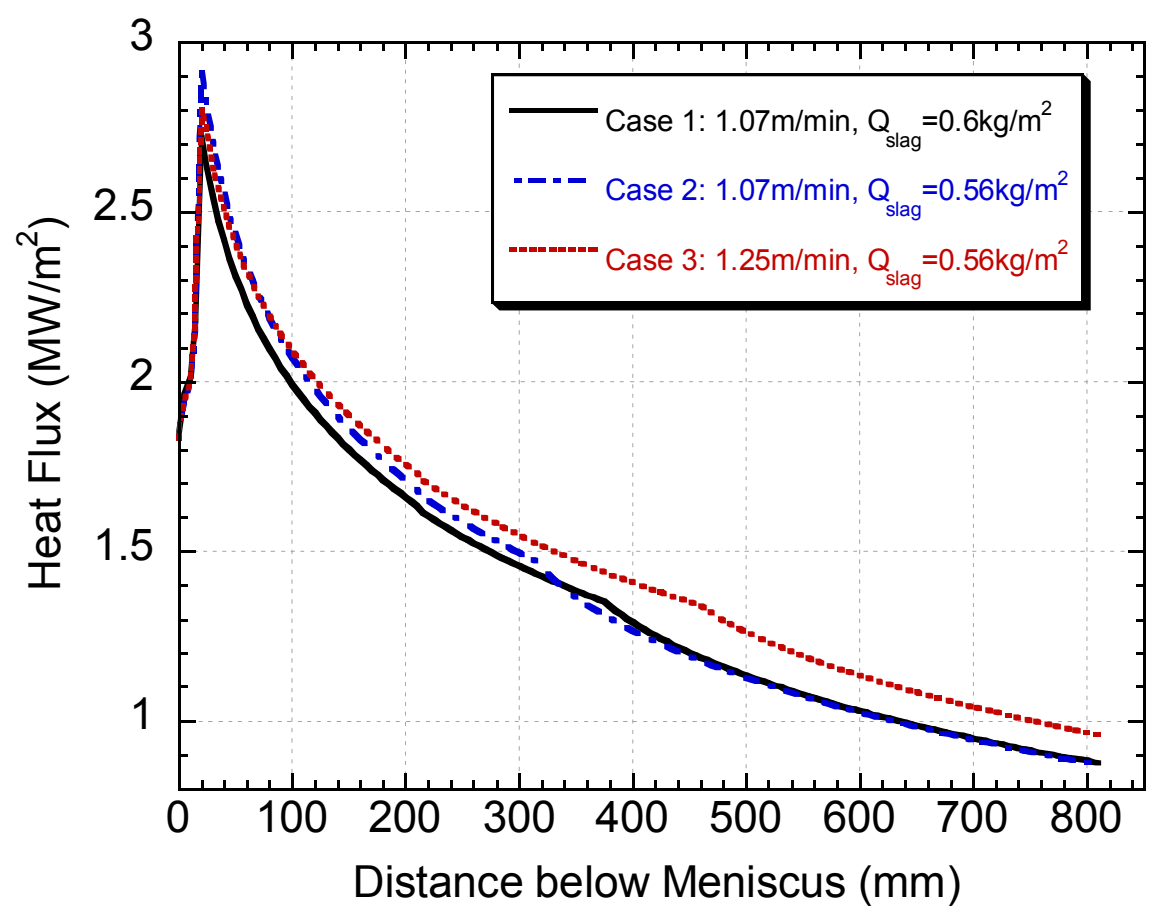

Figure 19. Effect of casting speed on heat flux profile 


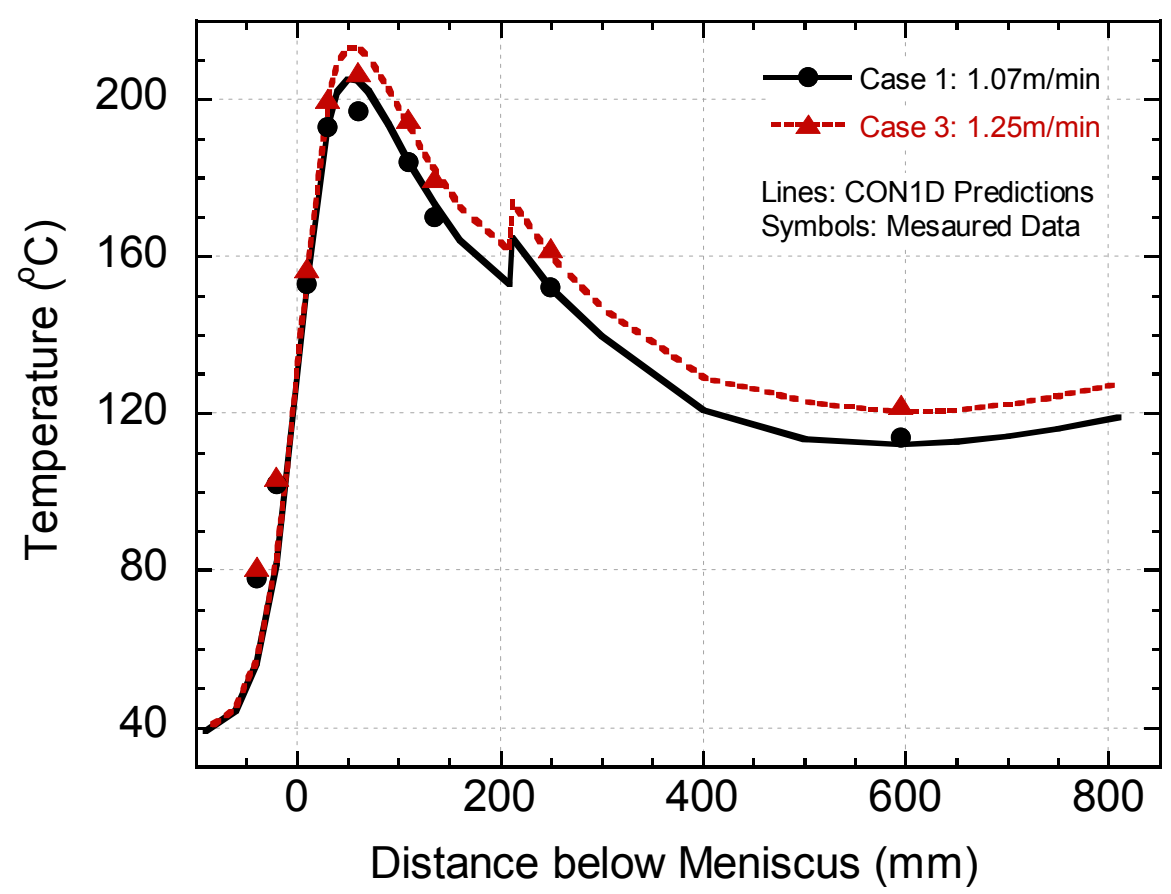

Figure 20. Effect of casting speed on mold temperature

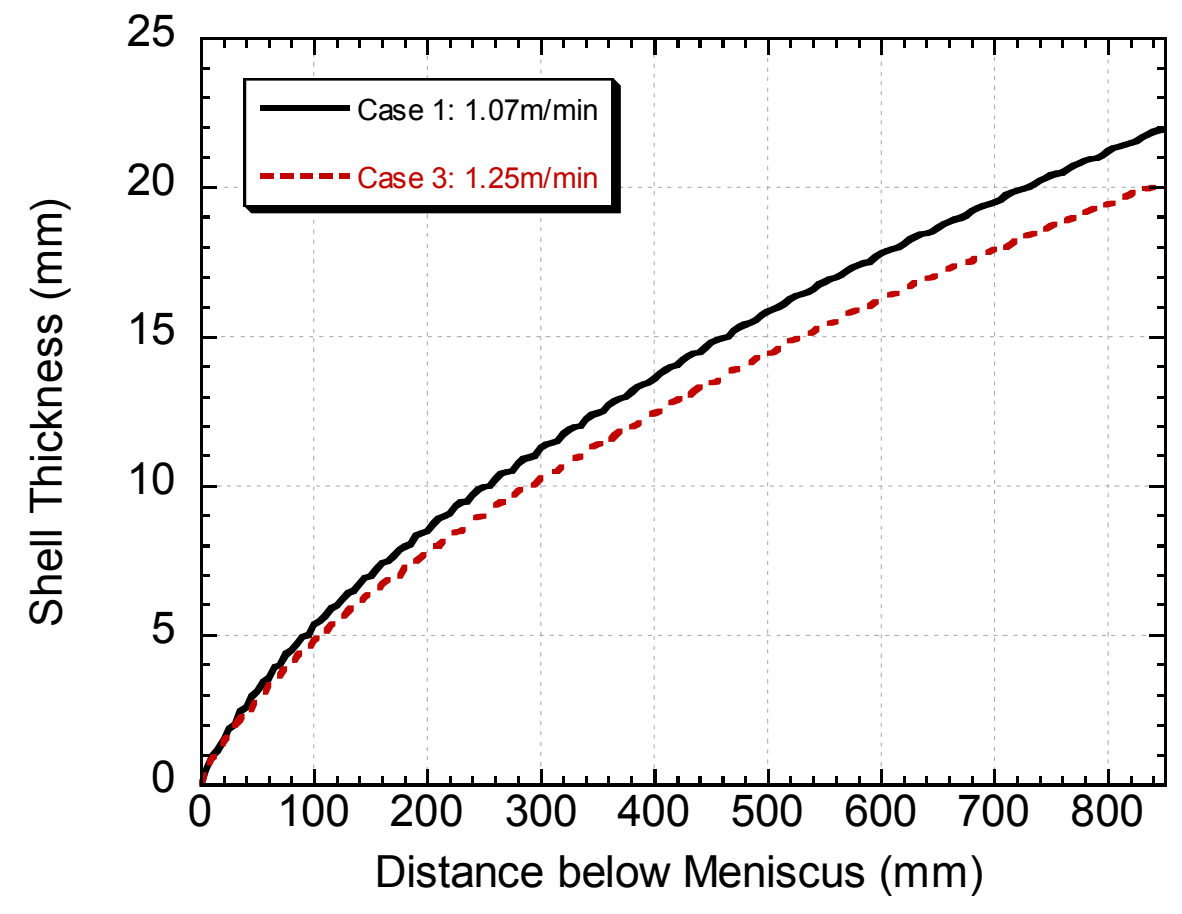

Figure 21. Effect of casting speed on shell thickness 


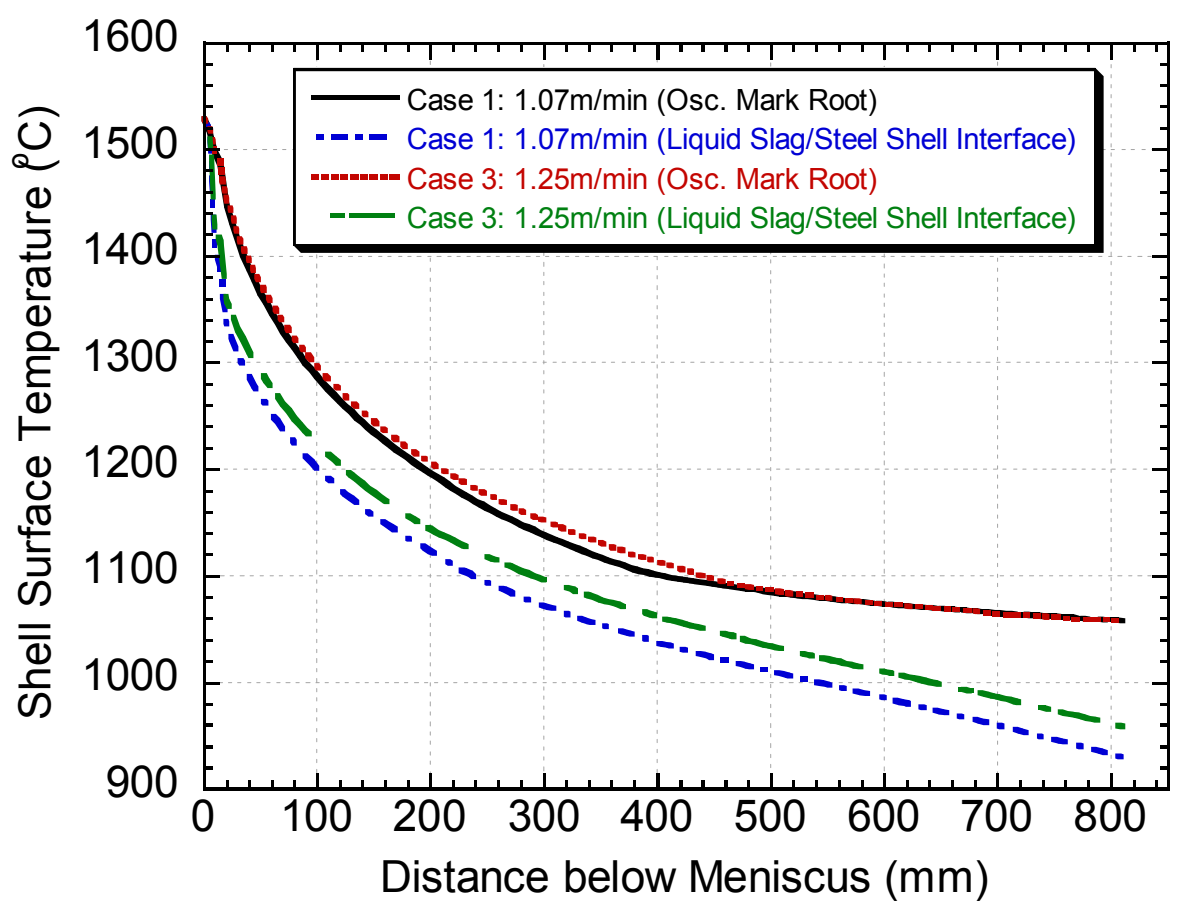

Figure 22. Effect of casting speed on steel shell surface temperature

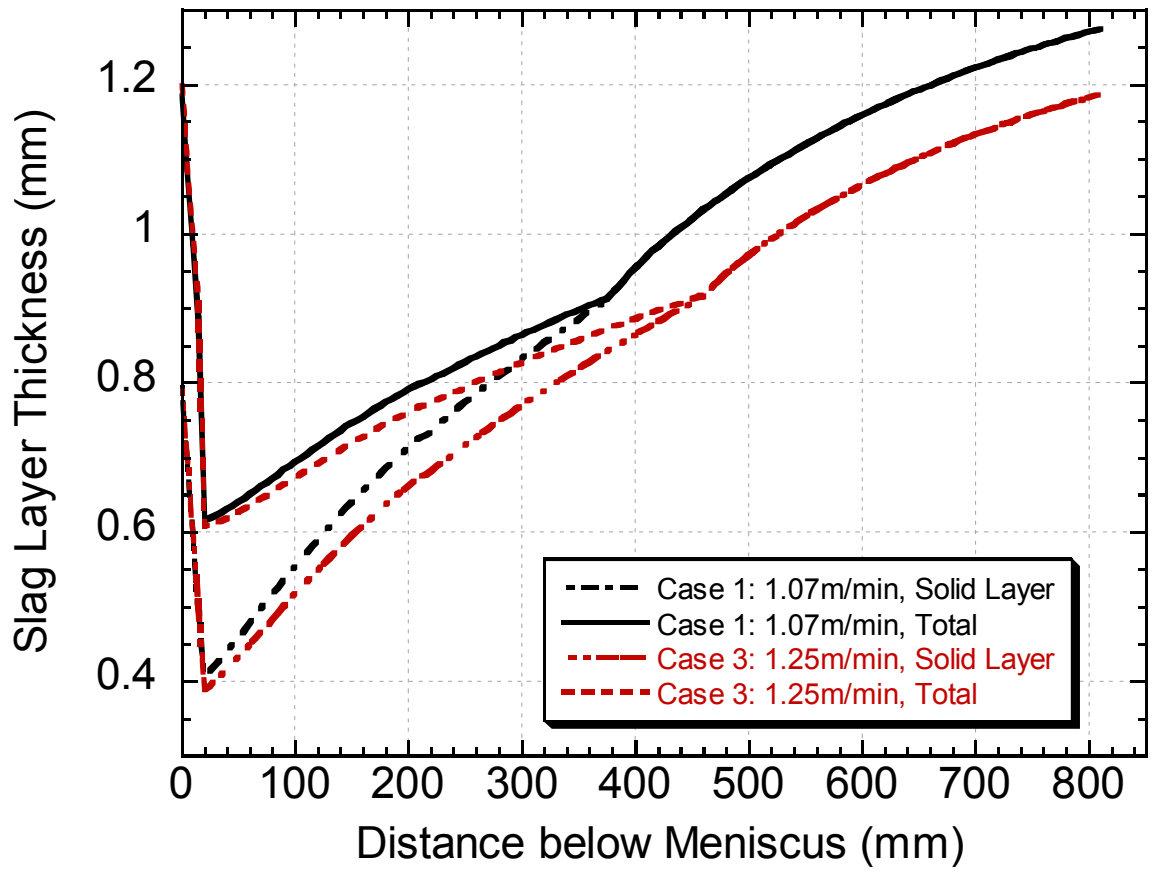

Figure 23. Effect of casting speed on slag layer thickness 


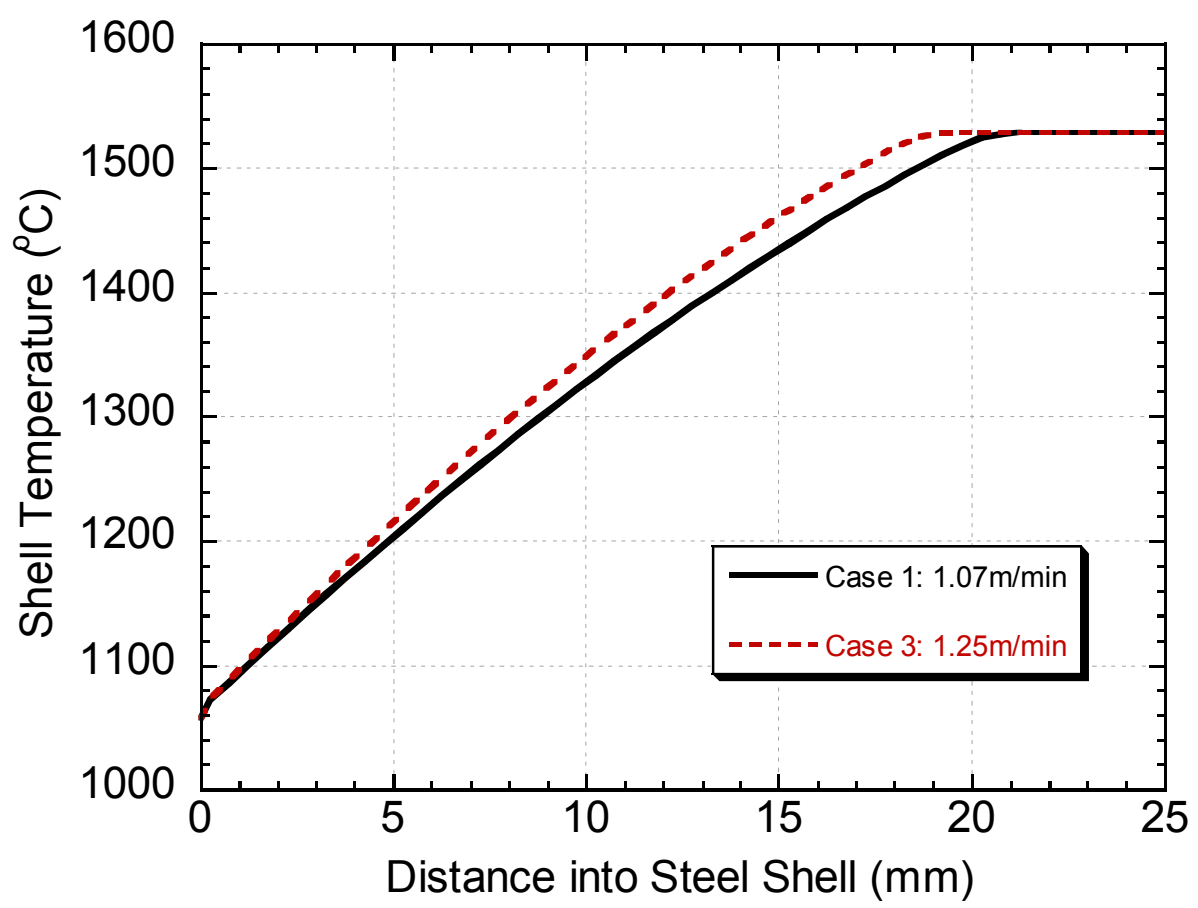

Figure 24. Effect of casting speed on shell temperature profile at mold exit

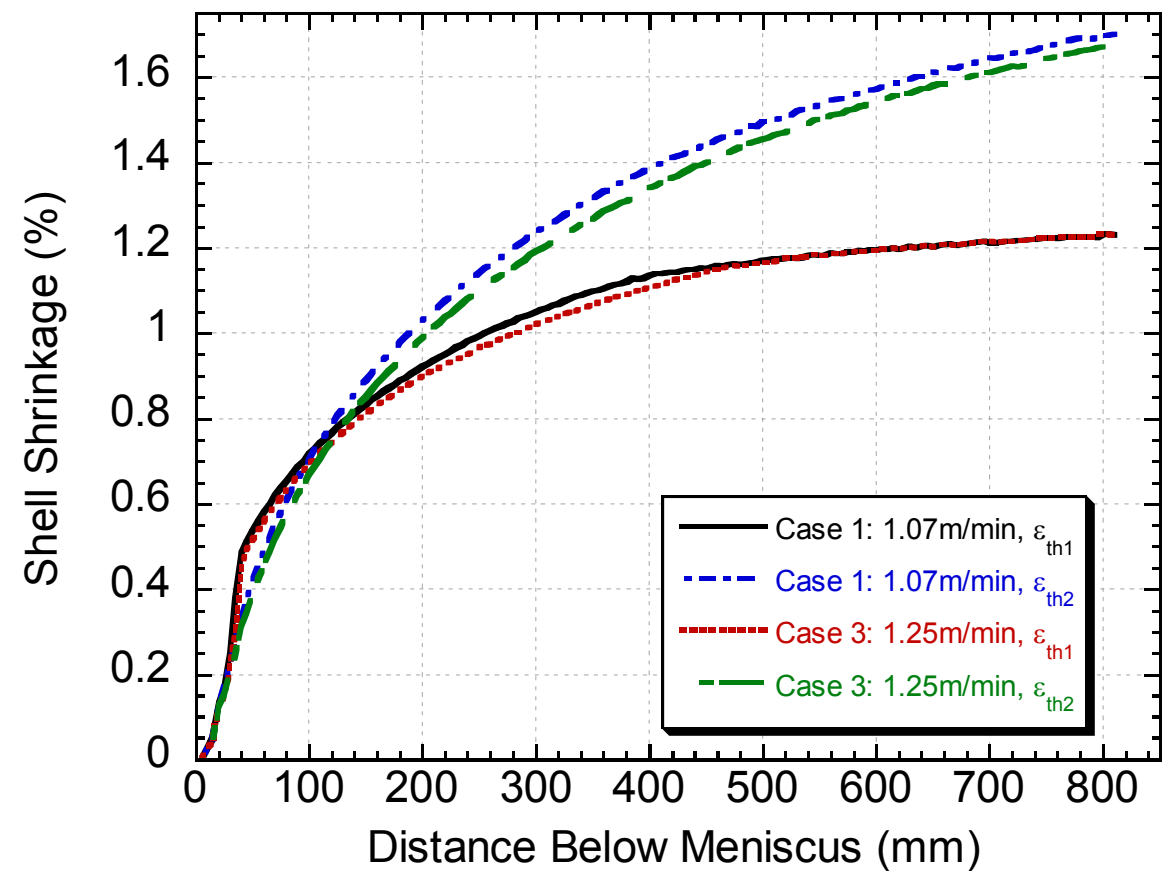

Figure 25. Effect of casting speed on shell shrinkage 